\title{
Sexual Modulation of Testosterone: Insights for Humans from Across Species
}

\author{
Katherine L. Goldey • Sari M. van Anders
}

Received: 20 June 2014 / Revised: 28 July 2014 / Accepted: 29 July 2014 /

Published online: 15 August 2014

C Springer International Publishing 2014

\begin{abstract}
Testosterone (T) is generally understood to influence sexual behavior, but how $\mathrm{T}$ responds to sexuality is less well characterized across vertebrate species. Here, we review and synthesize findings on sexual modulation of $\mathrm{T}$ in primates (including humans), birds, fish, and rodents, with attention to the specific elements of sexual situations that drive $\mathrm{T}$ responses. We use a comparative perspective to show how research with females and males from a wide distribution of taxa provides novel insights for understanding effects of sexuality on $\mathrm{T}$ in humans. Among other patterns, our cross-species synthesis highlights a) the importance of the context surrounding a sexual interaction, over and above specific sensory modalities, to sexual modulation of $\mathrm{T}$; $\mathrm{b}$ ) that changes in $\mathrm{T}$ and changes in sexual behavior or arousal do not always occur in concert; c) that sexual contexts may be especially likely to increase $\mathrm{T}$ when coupled with aggression or competition, but sexuality contributes to $\mathrm{T}$ profiles independently as well; and d) that variation in $\mathrm{T}$ responses may be adaptive in balancing behavioral and physiological costs and benefits of $\mathrm{T}$. We discuss how broadening the ways sexuality is defined, and especially decoupling sexuality from reproduction, would further clarify predictors and potential functions of sexually-modulated T. Overall, effects of sexuality on T across species highlight the malleability of androgens, particularly in response to the social environment. Not only does sexual behavior affect T, but the social environment in turn modulates the extent of sexuality's effect on T.
\end{abstract}

Keywords Sexuality $\cdot$ Testosterone $\cdot$ Androgen $\cdot$ Gender $\cdot$ Sex $\cdot$ Aggression

\section{Introduction}

Sexual behavior is a primary focus of study among researchers interested in evolution for obvious reasons - in almost all vertebrates, sex is essential for reproduction. Yet,

\section{K. L. Goldey}

Department of Psychology, University of Michigan, 530 Church St., Ann Arbor MI 48109, USA

\section{S. M. van Anders $(\square)$}

Departments of Psychology \& Women's Studies, Program in Neuroscience, Reproductive Sciences Program, Science, Technology, \& Society Program, University of Michigan, 530 Church St., Ann Arbor MI 48109, USA

e-mail:ssmva@umich.edu 
sexual behavior can serve many adaptive functions besides fertilization, including pair bond maintenance, conflict management, alliance formation, expression of dominance or power dynamics, experiencing pleasure, and resource acquisition (Abramson and Pinkerton 2002; Pfaus et al. 2012; Snowdon et al. 2006; Vasey and Sommer 2006; Wallen and Zehr 2004). Moreover, some sexual behaviors like solitary sexuality or masturbation may not serve an adaptive function, but are still evolutionarily relevant; i.e., they may be by-products of adaptive sexual behaviors (Vasey and Sommer 2006).

Just as ultimate functions of sexual behavior are more diverse than they might seem at first glance, the proximate situations in which sexual behavior occurs are highly varied obviously between species, but also among individuals within a species, and within individuals based on context. For example, a female Japanese macaque might mount another female or be mounted by a male (Vasey 2006); downy woodpeckers might perform sexual solicitations in the spring or in winter, outside of the breeding season (Kellam et al. 2004); and tufted capuchin monkeys can have sexual interactions ranging from one minute to one hour (Alfaro 2005). Far from just a stereotyped set of motor patterns, sexuality is complex in terms of behavior, context, and function. How do individuals regulate their behavior in response to such a diverse array of sexual contexts?

Hormones are key physiological mechanisms by which individuals adjust their behavior in response to changing social environments (Oliveira 2009). In particular, testosterone (T) is implicated in tradeoffs relevant to life-history strategies, such that high $\mathrm{T}$ is linked with competition (i.e., acquisition or defense of resources, including sexual partners or opportunities) and low $\mathrm{T}$ is linked with nurturance (i.e., warm, loving contact between partners, parents and offspring, or others) (van Anders et al. 2011). T and other androgens respond dynamically to social stimuli, such that T-behavior associations are often bidirectional or iterative (van Anders and Watson 2006). A critical role for $\mathrm{T}$ in the organization, activation, and maintenance of (male) sexual behavior has been clearly established via hormone administration and ablation studies (Adkins-Regan 2012; Munakata and Kobayashi 2010), but how T responds to sexual contexts across species is less well characterized, particularly compared to modulation of $\mathrm{T}$ by other social behaviors such as aggression, competition, and parenting.

Here, we review and synthesize findings on sexual modulation of $\mathrm{T}$ in fish, birds, rodents, and primates (including humans), with attention to the specific elements of sexual situations that drive $T$ responses. We chose the above taxa because enough data on sexual modulation of T exists in these groups to warrant review. Male rodents have received a thorough treatment in two reviews of sexual modulation of T (Gleason et al. 2009; Nyby 2008), and another contribution examined social modulation of $\mathrm{T}$ in male vertebrates by mating and parenting system (Hirschenhauser and Oliveira 2006). In contrast, we include research on females and males from a wide distribution of taxa focusing specifically on sexuality. We use the abbreviation $\Delta T$ for $\mathrm{T}$ responses to sexual stimuli or behaviors (i.e., sexually-modulated T), and we use sexuality to refer to sexual contexts broadly, encompassing sexual behavior and exposure to sexual cues. Below, we discuss several overarching themes that provide a backdrop for our review.

What Counts as Sexual?

What counts as 'sexual' when studying sexual modulation of T? Many accepted definitions of sexual behavior explicitly state or imply a reproductive function. For 
example, a review of the endocrinology of sexual behavior in fish defines sexual behavior as "a series of behavioral acts that are mostly sex specific, performed by sexually mature males and females, that include actions for gamete release and fusion, and are also ultimately for the production of offspring" (Munakata and Kobayashi 2010 , p. 456, emphasis in original). This definition arguably excludes a number of behaviors that could be sexual, including sexual behaviors between juveniles or prepubertal adolescents (Wallen and Zehr 2004), between individuals of the same sex (Bagemihl 1999; Bailey and Zuk 2009; Vasey and Sommer 2006), or between females and males during the non-breeding season or non-fertile periods of a female's cycle. Because these behaviors cannot result in fertilization, they are often conceptualized as socio-sexual at best rather than sexual. But, even if the ultimate function of a behavior is to facilitate adaptive social goals, this does not discount a role for sexual motivation or sexual pleasure; that is, a behavior could facilitate adaptive goals besides fertilization (or not be adaptive at all) and still be sexual (see Vasey and Sommer 2006). How do we know that a male rat smelling female pheromones is 'sexual', but a female Japanese macaque mounting another female while thrusting her pelvis is not? By limiting the study of sexuality to reproductive contexts and treating non-reproductive sexual contexts as "desexualized vehicles by which fitness-enhancing goals can be achieved" (Vasey and Sommer 2006, p. 13), we lose the opportunity to study behaviors that could yield both mechanistic and evolutionary insights (van Anders 2013).

For this review, we rely on a broad definition of sexuality that focuses on observable behaviors rather than reproductive functions. Following Vasey and Sommer (2006), we define sexual behavior as including courtship displays and interactions, sexual solicitations, mounting, and interactions involving genital contact between individuals (regardless of orgasm or penetration). Sexual cues include sensory stimuli from potential sexual partners or stimuli that commonly occur in concert with the behaviors listed above. While this definition of sexuality is relatively inclusive, we recognize that it too has limitations when applied across species. For example, this definition might not encompass all sexual interactions in fish. Some behaviors are ambiguous - singing in birds could occur within a courtship display or a territorial challenge - in these cases, social and environmental context are highly important in classifying a behavior. And, our definition is limited by the parameters of the studies we review (e.g., almost all studies of $\Delta \mathrm{T}$ to partner cues focus on other-sex stimuli).

What does all this have to do with hormones? How we define sexuality has implications for how we study it, and operational parameters shape the social and environmental cues animals are exposed to and the behaviors they have the potential to perform (e.g., a female rat in a testing cage with one male rat can only interact with that male, even though she would likely copulate with multiple sexual partners within the same time frame in the wild (McClintock et al. 1982)). In turn, sensory and behavioral experiences modulate physiological responses. The studies reviewed below define and measure sexuality in a number of different ways. In naturalistic or field studies, directionality and causal relationships are often difficult to establish; T may be elevated during periods of high sexual activity, but these periods may co-occur with intense competition for territories or low levels of parental behavior, making relative influences of behaviors on $\mathrm{T}$ challenging to separate. Laboratory experiments have the advantage of isolating specific sexual stimuli and establishing causal relationships with T. Yet, there is a tradeoff such that stripping sexuality from its context could either mask or 
exaggerate measurable hormone-behavior associations. For example, the extent to which female rhesus monkeys' sexual behavior is coupled with their hormonal state depends on the presence of other females and the resulting potential for harassment (Wallen 2001). Removing the 'context' (i.e., other females) obscures the ecological reality of hormone-sexuality associations in this species. Thus, the way sexuality is defined and measured dictates what contexts are studied in relation with $\mathrm{T}$, as well as the conclusions we can draw from research findings.

\section{Not All Sexuality is the Same - So Why Should All T Responses Be?}

Modulating T expression is one mechanism by which individuals regulate their behavior and physiology in response to competing life-history challenges (e.g., survival vs. reproduction) (Bribiescas 2001; Ketterson and Nolan 1992; Muehlenbein 2006; Oliveira 2009). T carries behavioral and physiological benefits and costs. Behaviorally, $\mathrm{T}$ promotes competition for resources, including sexual partners, territories, and status, but inhibits nurturant contact with offspring or partners (e.g., feeding, grooming) (van Anders et al. 2011). In some species, T increases locomotor activity and risk-taking behavior, which can facilitate sexual and territorial competition but increase the risk of injury (Ketterson and Nolan 1992; Wingfield et al. 2001). Physiologically, T allocates energy toward skeletal muscle anabolism and away from fat storage and immune functions (Bribiescas 2001; Muehlenbein and Bribiescas 2005; Muehlenbein 2006; Wingfield et al. 2001). While findings are complex, overall, androgens appear to have immunosuppressive effects in mammals and birds (Muehlenbein and Bribiescas 2005) and perhaps in fish (Yamaguchi et al. 2001), and humans down-regulate $\mathrm{T}$ in response to even mild immune challenges (Simmons and Roney 2009). Most research on physiological costs of $T$ focuses on males, but research with birds suggests some physiological costs are similar in females and males (e.g., delayed molt, immunosuppression) (Ketterson et al. 2005). Given the costs of T, researchers have hypothesized that individuals should limit $\mathrm{T}$ expression to the times it is most advantageous, such as when potential sexual partners are present (Muehlenbein 2006; Wingfield et al. 2001).

Several functions of T may be especially useful in sexual contexts, though there is debate about whether $\Delta \mathrm{T}$ is adaptive and if so, what its specific functions are. In addition to promoting intrasexual competition for partners, hypothesized functions for $\Delta \mathrm{T}$ include supporting physiological responses involved in sexual behavior, reducing anxiety and encouraging exploration, signaling quality to potential partners, and reinforcing associations between sexual activity and relevant contextual cues (Gleason et al. 2009; Nyby 2008; van Anders and Watson 2006). However, these potential benefits must be balanced with costs of elevated $T$, so it follows that $\Delta T$ should not occur with equal magnitude to every sexual encounter and instead should be sensitive to contextual parameters. For example, $\Delta \mathrm{T}$ should be responsive to cues that indicate the likelihood of a successful sexual encounter, such as the behavior and characteristics of a partner, the types of sensory stimuli present, or the presence of potential competitors. If partner compatibility is low or several higher-ranking competitors are present, mounting a $\mathrm{T}$ response could sacrifice energetic resources with little chance of benefit. Secondly, $\Delta \mathrm{T}$ should not occur (or at least should be less pronounced) when individuals are less equipped to handle the costs of elevated T, e.g., 
when energetic or immune resources are already depleted, or when an individual is currently pair bonded or parenting and inhibitory effects of $\mathrm{T}$ on nurturance could be costly. However, this prediction is complicated by the fact that maintaining lower baseline $\mathrm{T}$ and transiently elevating $\mathrm{T}$ in response to sexual or other social stimuli could be one successful strategy for offsetting T's energetic or behavioral costs (Wingfield et al. 2001). Thus, effects are likely nuanced such that the severity of an energy deficit or the stage of parenting could influence the extent to which even a shortterm $\mathrm{T}$ response is costly.

Finally, given that sexual encounters can serve many functions (e.g., expression of dominance vs. pair bond maintenance), $\Delta \mathrm{T}$ should be most pronounced when its downstream effects would be most advantageous. Some potential effects of $\Delta \mathrm{T}$, like decreased anxiety, might be especially beneficial in novel sexual situations or with new partners but unnecessary when sexuality occurs within an established pair bond (Gleason et al. 2009). Other effects, like T's rewarding properties, might be beneficial in a variety of sexual contexts; T could enhance the reward value of a particular location or a particular partner (Gleason et al. 2009). An important first step to elucidating the potentially context-dependent functions of $\Delta \mathrm{T}$ is to characterize the types of sexual experiences that elicit this response.

\section{Whose Behavior Does T Respond To?}

The above suggests that $\Delta \mathrm{T}$ should be sensitive to how a sexual situation is experienced - but whose experience? When Japanese quail copulate, a male chases a female, pulls her by the head or neck feathers with his beak (often while she attempts to run away), and eventually climbs onto her back while forcing her head backwards (Persaud and Galef 2005). Copulation is rewarding for male quail (Gutierrez and Domjan 1997) but aversive for females - which is not surprising given that males' behavior during copulation is potentially injurious to females (Persaud and Galef 2004, 2005). Are a male and female quail having the same sex? And given the sharp contrast in their experiences, it is reasonable to expect they would have similar physiological responses?

Japanese quail are an extreme example but, in any sexual interaction, experiences can differ between the two (or more) individuals involved. Whether an individual's own behaviors or cues from a partner's behaviors more strongly drive $\Delta \mathrm{T}$ is an open question. Classic experiments with ring doves showed that answering such a question is complex - researchers originally thought that a male vocalization induced ovulation in a female; instead, it is her response to his calls that is key (Cheng 2003). Researchers have suggested that $\Delta \mathrm{T}$ could signal mate quality to potential partners (Gleason et al. 2009; Nyby 2008); if this is the case, the ability to stimulate or detect $\Delta \mathrm{T}$ could be under selection in addition to $\mathrm{T}$ release itself. In our review, we especially highlight studies that explore how the dynamics of interactions within a pair modulate $\mathrm{T}$.

\section{Why Consider Sexual Modulation of T Across Species?}

Comparative research is valuable to understandings of sexual modulation of $\mathrm{T}$ (and social neuroendocrinology more generally) because it can reveal both shared principles and diversity across species (Adkins-Regan 2009, 2012; Oliveira 2009; van Anders 2013). Attention to a species' mating, parenting, and social systems yields important 
insights for how and why sexuality might affect $\mathrm{T}$. The experience of sexual activity is arguably different for common marmosets, who form long-lasting pair bonds, than for ring-tailed lemurs, where females mate with multiple males and vice versa during a brief period of female fertility. To the extent that they shape the contexts in which sexuality occurs, social, mating, and parenting systems may influence the hormonal consequences of sexual activity. Of course, humans are no exception in possessing both shared patterns and species-specificities, and an especially important human particularity is the presence of social constructs, i.e., phenomena created and developed through cultures and societies (van Anders 2013).

A comparative perspective illustrates when findings from humans generalize to other species and vice versa, so understanding how sexual modulation of $\mathrm{T}$ works across species is important for understanding it in humans (Adkins-Regan 2009; van Anders 2013). Synthesizing research from a broad array of species, rather than just a few model species, more strongly clarifies when the dynamics of $\Delta \mathrm{T}$ in humans reflect conserved roles for $\mathrm{T}$ across vertebrates versus human-specific patterns (Goodson 2013). Wallen (2001) highlighted the value of a comparative framework by showing how human-specific particularities, such as actively preventing pregnancy or increasing sexual frequency on weekends, might obscure or overwhelm measurable associations between hormones and sexual behavior that are present in other primates. Findings from non-human species can also provide unexpected insights for humans, partially because researchers can observe sexual behaviors more directly in non-human species. For example, we discuss how research on $\Delta \mathrm{T}$ in female birds helps generate novel hypotheses regarding women's T responses to visual erotica (see Sexual Modulation of $\mathrm{T}$ in Birds).

We organize the next sections of this review by the taxa in which sexual modulation of $\mathrm{T}$ is most widely studied — primates (including humans), birds, fish, and rodents to facilitate comparisons between species with different mating, parenting, and social systems within each taxon, but we also highlight parallels across taxa, especially between humans and other species, when they occur. For each taxon, we review evidence that $T$ responds to sexual contexts, discuss predictors of $\Delta T$, and briefly touch on potential functional sequelae of $\mathrm{T}$ responses.

\section{Sexual Modulation of $\mathbf{T}$ in Primates}

Anthropoid primates, including humans, are unique in that females' physical capacity to mate is decoupled from periods of fertility (Wallen and Zehr 2004). Because of this, sexual behavior is especially sensitive to social context and likely to serve functions besides reproduction, such as alliance formation or affiliation (Wallen and Zehr 2004). Diverse social roles for sexuality in female and male primates suggest that social context may regulate how sexual behavior affects $\mathrm{T}$, so we focus particularly on how factors such as aggression, competition, pair bonding, and parenting affect sexual modulation of $\mathrm{T}$ in both longer-term contexts (e.g., links between $\mathrm{T}$ and sexual behavior patterns across seasons) and acute contexts (i.e., T responses to discrete sexual events).

Acute $\mathrm{T}$ responses to different modalities of sexual stimuli have been examined more extensively in humans than in other primates; as a whole, this research indicates that while humans' $\mathrm{T}$ can respond to very subtle sexual cues, $\mathrm{T}$ does not respond to 
sexual stimuli or behavior in every context (for the physiological cascade of events leading to $\Delta \mathrm{T}$ in humans, see Fig. 1). Sexual thoughts in the absence of sensory stimuli are sufficient to increase $T$ in women (Goldey and van Anders 2011). In men, sexual thoughts do not increase T overall (Goldey and van Anders 2012), but the content of thoughts is linked with T responses, such that lower inclusion of nurturant content (i.e., related to warm, loving aspects of sexuality) predicted higher $\Delta \mathrm{T}$ (Goldey et al. 2014). Consistent with effects of sexual thoughts on T, women's T increases in anticipation of sex (Hamilton and Meston 2010; van Anders et al. 2007), and a classic study involving a single male subject suggests men's T may do so as well (Anonymous 1970). Multiple studies have shown that viewing erotic films increases $\mathrm{T}$ in men (Hellhammer et al. 1985; Pirke et al. 1974; Redoute et al. 2000; Stoleru et al. 1993, 1999) (cf. Carani et al. 1990; Rowland et al. 1987), but three studies have found that erotic films do not significantly change T in women (Hamilton et al. 2008; Heiman et al. 1991; van Anders et al. 2009), though means were in the expected directions with large between-subjects variability (Hamilton et al. 2008; van Anders et al. 2009).

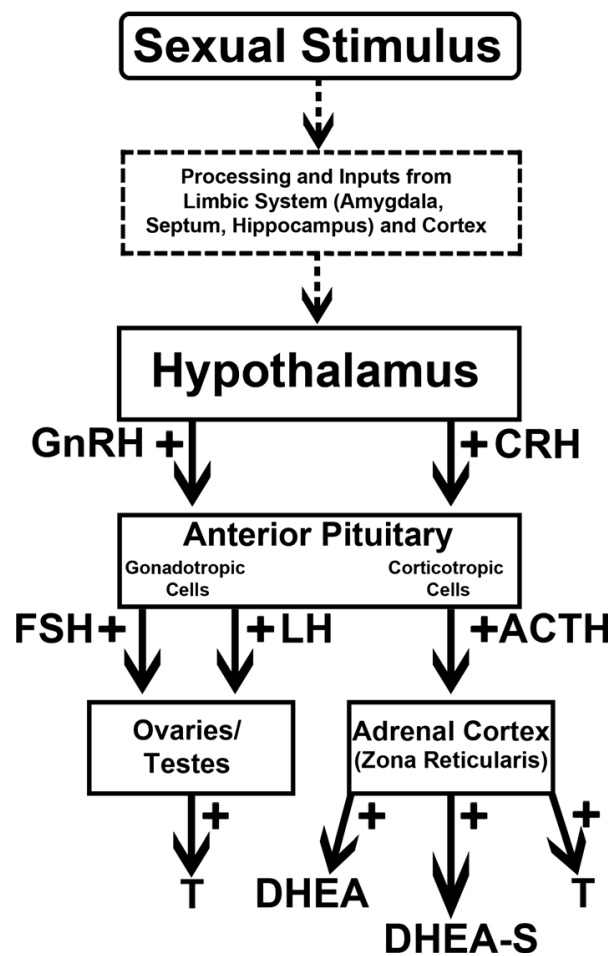

Fig. 1 Sexuality-to-Testosterone Cascade: The neural processing of sexual stimuli that leads to androgen release in humans. The adrenal cortex is likely to be a larger contributor to sexually-modulated testosterone $(\Delta \mathrm{T})$ in women, whereas the gonads are likely larger contributors to $\Delta \mathrm{T}$ in men. An important role for upstream releasers like kisspeptin and neurokinin B in stimulating GnRH release has been established in nonhuman animals (Navarro 2012), but these releasers are less well understood in humans (Chan 2013). Given the rapidity of $\Delta \mathrm{T}$ in some contexts, mechanisms besides the hypothalamic-pituitary-gonadal or hypothalamicpituitary-adrenal axes (e.g., changes in concentrations of binding proteins) may also contribute to $\Delta \mathrm{T}$ (Flinn et al. 2012). Abbreviations: GnRH = Gonadotropin-releasing hormone; $F S H=$ Follicle-stimulating hormone; $\mathrm{LH}=$ Luteinizing hormone; $\mathrm{CRH}=$ Corticotropin-releasing hormone; $\mathrm{ACTH}=$ Adrenocorticotropic hormone; DHEA = Dehydroepiandrosterone; DHEA-S = Dehydroepiandrosterone sulfate 
What about $\Delta \mathrm{T}$ in response to sexual behavior in humans? Partnered sexual activity (defined as intercourse in most studies) increases $\mathrm{T}$ in women, with mixed results in men (Dabbs and Mohammed 1992; Escasa et al. 2011; Fox et al. 1972; Hirschenhauser et al. 2002; Kraemer et al. 1976; Lee et al. 1974; Sagarin et al. 2009; Stearns et al. 1973; Strom et al. 2012; van Anders et al. 2007). Whereas women's T increases rapidly (within $15 \mathrm{~min}$ ) after sexual activity (van Anders et al. 2007) and returns to baseline levels by the following morning (Prasad et al. 2014; van Anders et al. 2007), two studies suggest that men's T may respond to sexual activity at a delay (e.g., the morning after the activity) (Hirschenhauser et al. 2002; Kraemer et al. 1976). A delayed response in men is consistent with findings in captive male rhesus monkeys, where T responses to sexual activity are most evident after at least $24 \mathrm{~h}$ (Bernstein et al. 1977; Phoenix et al. 1977). In men, $\Delta \mathrm{T}$ also seems more likely to occur following sexual interactions that could be perceived as especially salient or competitive, such as interactions with unfamiliar or multiple partners or at a sex club (Escasa et al. 2011; Hirschenhauser et al. 2002). In these interactions, $\Delta \mathrm{T}$ could function to alleviate anxiety that might occur with an unfamiliar partner or location. Finally, addressing the question of whether partner presence is necessary for $\mathrm{T}$ responses to sexual behavior, solitary masturbation produced a marginally significant increase in $\mathrm{T}$ in women (Exton et al. 1999), whereas most studies find that masturbation does not significantly change men's $\mathrm{T}$ (Exton et al. 2001; Fox et al. 1972; Kruger et al. 1998, 2003; Strom et al. 2012; Stárka et al. 2006) (cf. Purvis et al. 1976).

How might we make sense of this seemingly contradictory pattern of findings? Why would sexual thoughts increase women's T when visual stimuli do not, and why would sexual behavior have inconsistent effects on men's T if visual stimuli are sufficient for $\Delta \mathrm{T}$ ? It may be that the context surrounding a sexual stimulus is more important for $\mathrm{T}$ than stimulus modality. van Anders (2013) predicted that sexual contexts oriented around genital/erotic pleasure, power, or jealousy will increase $\mathrm{T}$, whereas sexual contexts oriented around nurturance (e.g., closeness, pair bonding) will decrease T. For example, perhaps viewing erotic films typically involves more erotic pleasure and positive affect for men than women, given different past histories and socialization experiences around pornography (van Anders 2013).

A complementary literature addresses humans' T responses to stimuli from potential partners, rather than to explicitly sexual stimuli. Heterosexual men show rapid $\mathrm{T}$ responses to brief (5-15 $\mathrm{min}$ ) social interactions with unfamiliar women (Roney et al. 2003, 2007; van der Meij et al. 2008), and close physical contact (dancing) increases $\mathrm{T}$ in women and men (Murcia et al. 2009). Physical presence of potential mates does not seem necessary for this response, as exposure to pictures of other-sex faces increased $\mathrm{T}$ in heterosexual women and men (Zilioli et al. 2014), and a simulated (videotaped) courtship interaction increased women's T (Lopez et al. 2009). Like $\Delta \mathrm{T}$ to sexual stimuli and behaviors, these responses are not all-or-nothing and are sensitive to context. For example, men in a rural Dominican community had lower $\mathrm{T}$ when interacting with a close friend's female partner than when interacting with an unpartnered woman or a woman in a relationship with someone who was not a close friend (Flinn et al. 2012). Given the importance of social alliances in humans, inhibiting neuroendocrine responses to close friends' mates could provide one mechanism for maintaining cooperation and limiting competition between in-group members (Flinn et al. 2012). 
Individual factors, including androgen receptor gene polymorphisms, baseline hormone concentrations, personality, and (inconsistently) sexual experience, also explain variation in men's $\Delta \mathrm{T}$ to potential mates. Men with the greatest number of CAG repeats in the androgen receptor gene, indicative of the lowest androgen receptor activity, showed the smallest $\Delta \mathrm{T}$ in response to a social interaction with a woman (Roney et al. 2010). Thus, androgen receptor activity may increase the sensitivity of neural circuits responsible for T release (Roney et al. 2010). Furthermore, men with higher baseline cortisol had lower $\Delta \mathrm{T}$ (Roney et al. 2010), perhaps because higher baseline cortisol reflects an energy deficit (Peters et al. 2004) or chronic stress and thus lack of energetic resources to expend on pursuit of sexual activity. Finally, a more aggressive, dominant personality predicted higher $\Delta \mathrm{T}$ (van der Meij et al. 2008), and one study found that $\Delta \mathrm{T}$ only occurred in men with recent sexual experience (Roney et al. 2003), though three others did not replicate this finding (Roney et al. 2007, 2010; van der Meij et al. 2008). Together, these results suggest that $\Delta \mathrm{T}$ to potential mates occurs most strongly in individuals for whom $\Delta \mathrm{T}$ is more likely to translate into a behavioral response given personality and genetic factors, and/or those who are best prepared for costs of $\Delta \mathrm{T}$ or sexual activity.

$\mathrm{T}$ responses to interactions with potential mates have been linked with behaviors relevant to courtship or sexual competition. For example, women's $\Delta \mathrm{T}$ to simulated courtship interactions positively predicted sexual and romantic interest (Lopez et al. 2009). In men, higher $\Delta \mathrm{T}$ predicted more 'show-off' or display behaviors (e.g., talking about oneself) in conversations with women in the laboratory (Roney et al. 2003, 2007) and increased risk-taking behavior in a naturalistic study (Ronay and von Hippel 2010). It is unclear whether $\Delta \mathrm{T}$ increases courtship behaviors or whether displaying more of these behaviors leads to higher $\Delta \mathrm{T}$. However, one recent study found that heterosexual men's $\mathrm{T}$ responses to competition predicted affiliative and display behaviors in a subsequent interaction with a woman, suggesting that changes in $\mathrm{T}$ can facilitate courtship behaviors (van der Meij et al. 2012). Overall, these findings, together with those on $\Delta \mathrm{T}$ to partnered sexual activity, reinforce the pattern that interactions perceived or experienced as competitive (as may occur when meeting a potential partner for the first time) lead to higher $\Delta \mathrm{T}$.

Paralleling findings that especially salient or competitive sexual interactions lead to the strongest short-term increases in men's T, research on male non-human primates suggests that intrasexual competition may underlie apparent links between $\mathrm{T}$ and sexuality in longer-term contexts. For example, male chacma baboons in consortships with females had higher $\mathrm{T}$ than non-consorting males, but this link was secondary to associations between $\mathrm{T}$ and dominance rank, which controls access to mates in this species (Beehner et al. 2006). Sexual behavior did not predict $\mathrm{T}$ when controlling for aggression in male ring-tailed lemurs (Cavigelli and Pereira 2000) and, in male black howlers, $\mathrm{T}$ was linked with the potential for competition from extragroup males rather than with sexual behavior (Rangel-Negrin et al. 2011). In chimpanzees, males' $T$ increased in the presence of parous but not nulliparous receptive females; male chimpanzees copulate with both parous and nulliparous females but only parous females elicit male-male competition, suggesting that the rise in $\mathrm{T}$ is more closely coupled with sexual competition than sexual behavior itself (Muller and Wrangham 2004). Finally, male muriquis, who show very low levels of aggression, do not show consistent parallels between T profiles and copulatory periods (Strier et al. 1999, 2003). 
Together, these findings suggest links between males' $\mathrm{T}$ and sexual behavior, when they occur, may result from heightened intermale aggression during periods of female receptivity.

An interesting exception to the above pattern is the tufted capuchin monkey. In capuchins, sexuality-related measures (consortships, copulation frequency, females in behavioral estrus, and days of sexual activity) positively predicted $\mathrm{T}$ in males, but rank and aggression-related measures did not (Lynch et al. 2002). In this species, consortships are maintained by females, who actively solicit males with frequent approaches and withdrawals accompanied by vocalizations; males typically do not reciprocate with sexual behaviors until after some delay (Alfaro 2005; Carosi and Visalberghi 2002). Perhaps sexual stimuli are especially important for $\mathrm{T}$ in species where female proceptivity and mate choice, more so than male-male aggression, contribute to males' reproductive success (Lynch et al. 2002).

While the above studies examined sexual modulation of $\mathrm{T}$ over longer time-scales (e.g., seasons), a few have examined how more discrete sexual events affect $\mathrm{T}$ in nonhuman primates. Short-term (30 min to $2 \mathrm{~h}$ ) exposure to olfactory cues from ovulatory or pre-ovulatory females increased $\mathrm{T}$ in male common marmosets (Ziegler et al. 2005) and stumptailed macaques (Cerda-Molina et al. 2006). Some research suggests that olfactory cues may also affect androgens in humans. In one study, exposure to male axillary extract shortened the interval between luteinizing hormone (LH) pulses in heterosexual women (Preti et al. 2003), but studies on the effects of women's ovulatory scents on men's T have yielded conflicting results (Cerda-Molina et al. 2013; Miller and Maner 2010; Roney and Simmons 2012).

Responses to ovulatory cues are contextually situated in humans and non-human primates: in men, knowledge that the odors are from women seems to be important for $\Delta \mathrm{T}$ (Roney and Simmons 2012), as does the specific source of the odors, with vulvar odors eliciting a longer-lasting effect on $\mathrm{T}$ than axillary odors (Cerda-Molina et al. 2013). Based on these results, Cerda-Molina and colleagues (2013) hypothesized that $T$ responses to vulvar odors could provide a mechanism for cunnilingus to increase sexual interest in the partner performing stimulation in addition to the partner receiving it; this hypothesis underscores the importance of studying $\Delta \mathrm{T}$ to sexual activities besides penis-vagina intercourse. For common marmosets, who are socially monogamous, $\Delta \mathrm{T}$ to novel female odors depends on a male's pair bonding and parenting status, such that $\mathrm{T}$ increased in single males but not those currently parenting; pair bonded males not currently parenting showed an intermediate T response (Ziegler et al. 2005). Thus, pair bonded males, especially father males, may inhibit their neuroendocrine arousal responses to sexual stimuli provided by any individuals except their own mate (Snowdon et al. 2006). Determining whether father males would respond to their own mates' cues with $\mathrm{T}$ increases would clarify whether pair bonding and parenting inhibit $\Delta \mathrm{T}$ in general (perhaps to avoid any suppressive effects of $\mathrm{T}$ on nurturance), or simply make $\Delta \mathrm{T}$ more selective, responding only to the mate's cues.

Pair bonding and parenting contexts may modulate how $\mathrm{T}$ is coupled with sexuality in humans as well. Hirschenhauser and colleagues (2002) found that bidirectional links between men's daily $\mathrm{T}$ levels and sexual activity were most pronounced in men who wanted children with their current female partner. Furthermore, these T-sexual activity patterns followed a monthly trajectory, suggesting that pair bonded men who desire children can respond hormonally and behaviorally to their partner's fertility status 
(Hirschenhauser et al. 2002). In a longitudinal study, Gettler et al. (2013) found that men who reported more frequent sexual intercourse with their partners experienced less of a decline in T during the transition to parenthood. Women's $\mathrm{T}$ is also lower when they are parenting young children (Kuzawa et al. 2010), raising questions as to how sexual activity could be implicated in changes in $\mathrm{T}$ as women transition to parenthood.

In humans and other primates, what the sexual stimulus is may be less important for $\mathrm{T}$ than the context in which it occurs. The extent to which sexual interactions are characterized by competition or are likely to elicit aggression or harassment affects links between sexuality and $\mathrm{T}$, as does pair bonding or parenting status of the individuals involved. Findings that subtle sexual stimuli can affect women's T raise the question of whether sexuality modulates $\mathrm{T}$ in female non-human primates. Thus far, research has shown that social context clearly modulates the extent to which hormones influence primate female sexuality (Wallen 2001), but whether and how context affects $\mathrm{T}$ responses to sexuality remains an open question.

\section{Sexual Modulation of $\mathbf{T}$ in Birds}

Hormone-behavior relationships are extensively studied in birds partly due to the diversity of their mating and social systems. While $90 \%$ of bird species are socially monogamous, sexual monogamy is much rarer (Griffith et al. 2002), and polyandry, polygyny, polygynandry, and cooperative breeding are also present among birds. Research with birds in both captive and field environments is common, often within the same species, such that naturalistic observations of sexual behavior can be combined with more controlled laboratory investigations. Thus, definitions of 'sexual interactions' range from the relatively broad (e.g., presence and proximity of potential sexual partners; performance of courtship displays) to the very specific (e.g., cloacal contact and muscle activity; see Adkins-Regan and Leung 2006) depending on study methods. An especially important consideration in birds is seasonality, such that sexual behavior - and T-behavior associations - are highly dependent on photoperiod (Wingfield et al. 1990).

In many species of birds, especially those living in temperate zones, males' $\mathrm{T}$ is higher during the breeding season than at other times of the year (Wingfield et al. 1990). The Challenge Hypothesis (Wingfield et al. 1990), which has guided much research on $\mathrm{T}$ and social behavior in birds and other vertebrates (Hirschenhauser and Oliveira 2006), proposes that $\mathrm{T}$ levels above a breeding season baseline are a function of male-male competition for territories or mates. However, because sexual interactions have received relatively less attention than male-male competition, it is less clear to what extent sexual cues and behavior contribute to elevated T. Males' T is generally elevated when their mates or other females in the population are fertile (Peters et al. 2001; Wingfield et al. 1990); is the higher T in response to heightened mate guarding and aggressive interactions with other males, as seems to be the case in some primates, or to the sexual stimuli provided by females (Goymann et al. 2007; Pinxten et al. 2003)?

Several pieces of evidence suggest that female cues and behavior can shape males' $\mathrm{T}$ profiles. Females' solicitation behaviors regulated the transition from the higher-T courtship phase to the lower-T incubation phase in male white-crowned sparrows 
(Moore 1982) and male ring doves (O’Connell et al. 1981b). Similarly, the presence of soliciting females, compared to females that did not perform precopulatory displays, potentiated the rise in $\mathrm{T}$ in male sparrows exposed to long days (Moore 1983). Furthermore, male ring doves' $\mathrm{T}$ increased in response to pairing with a gonadally intact female but not an ovariectomized female (O'Connell et al. 1981a). Although males' $\Delta \mathrm{T}$ was not significantly correlated with either their own or their mates' courtship behaviors, only female behavior differed between the gonadally intact and ovariectomized conditions, suggesting female sexual behavior may contribute to $\Delta \mathrm{T}$ more so than males' own behavior (O'Connell et al. 1981a). In a more recent and parallel finding, male European starlings' $T$ increased after brief exposure to a female compared to a control condition, even in a subset of males who showed no behavioral response to the female (Pinxten et al. 2003).

A couple aspects of these findings in birds are analogous to those in humans and other primates. First, T changes and behavioral changes may not occur in concert, as evidenced by findings in European starlings and capuchin monkeys that cues from a partner can elicit $\Delta \mathrm{T}$ even in the absence of one's own behavioral responses (Lynch et al. 2002; Pinxten et al. 2003). Similarly, evidence for whether $\Delta \mathrm{T}$ is linked with changes in genital or psychological sexual arousal in humans is highly mixed; $\Delta \mathrm{T}$ is not clearly correlated with changes in arousal (Carani et al. 1990; Goldey and van Anders 2011, 2012; Heiman et al. 1991; Pirke et al. 1974; Rowland et al. 1987; Stoleru et al. 1993; van Anders et al. 2009). Second, in both biparental birds and humans, sexual behavior offsets a decline in males' T when parenting (Gettler et al. 2013; Moore 1982; O'Connell et al. 1981a), implying a role for T-sexuality links in coordinating the transition from earlier stages of a pair bond to parenting.

In birds, the importance of female behavior in eliciting males' $\Delta \mathrm{T}$ suggests hormone responses could function to coordinate the timing of reproduction within pairs (Moore 1983; O’Connell et al. 1981b; Pinxten et al. 2003). This coordination could be especially crucial for biparental species that tend toward social monogamy, like white-crowned sparrows, ring doves, and European starlings (though male European starlings are facultatively polygynous (Sandell et al. 1996)). Importantly, not all male birds show $\Delta \mathrm{T}$. Sexual interactions with females did not increase $\mathrm{T}$ in male Japanese quail (Delville et al. 1984; Meddle et al. 1997), and housing with females had little to no effect on T in male brown-headed cowbirds (Dufty and Wingfield 1986) or Willow ptarmigan (Stokkan and Sharp 1980). That males of these species, which are nonpaternal, highly aggressive, and/or tend toward polygyny, failed to show $\Delta \mathrm{T}$ is consistent with predictions of the Challenge Hypothesis, such that $\mathrm{T}$ may be already maximally elevated in these species and thus less malleable in response to social challenges (Wingfield et al. 1990). On the whole, research with male birds thus far suggests an important role for species' life-history factors (mating, social, and parenting systems) and a partner's behavior in determining $\Delta \mathrm{T}$.

Though studies on $\Delta \mathrm{T}$ in male birds certainly outnumber those in females, research with birds has been key to elucidating the evolved role of $\mathrm{T}$ in females (Ketterson et al. 2005). As in males, cues from a partner are important for $\Delta \mathrm{T}$ in females. Female canaries showed higher androgen responses to male song experimentally manipulated to be 'attractive' compared to less attractive song (Marshall et al. 2005). Notably, auditory cues are important for males' $\mathrm{T}$ responses as well, such that deafening male ring doves blocks their $\mathrm{T}$ response to females (O'Connell et al. 1981a). Although 
female European starlings do not show T responses to interactions with males, they do show LH responses, especially when paired with a male who had previously won a territorial contest (Gwinner et al. 2002). Interestingly, for males in this study, the strongest predictor of $\mathrm{T}$ responses was the presence of nest boxes, which may elicit $\mathrm{T}$ release because of their association with sexual or agonistic encounters (Gwinner et al. 2002).

In female Japanese quail, characteristics of a partner and the sexual interaction itself drive $T$ responses. Overall, female quails' $\mathrm{T}$ did not differ significantly from baseline to five minutes post-mating, although the means were in the expected direction, with higher T post-mating (Correa et al. 2011). However, females who experienced more mounts or were mated to males in better body condition had higher $\Delta \mathrm{T}$, and in turn, post-mating $\mathrm{T}$ predicted parameters relevant to maternal investment, specifically offspring sex ratio and the proportion of fertilized eggs (Correa et al. 2011). Especially in a species like Japanese quail, where males can force copulation, sensitivity of hormone responses to parameters of the sexual interaction would provide a mechanism for females to adjust their parental investment post-copulation and minimize costs of mating with unattractive males (Correa et al. 2011).

Overall, there is clear evidence that androgens respond to traits that signal partner quality or attractiveness in female birds, raising questions of whether this might reflect a broader pattern across taxa. If partner quality is important for $\Delta \mathrm{T}$, could this be why women show $\mathrm{T}$ responses to sexual thoughts and partnered sexual activity, but not visual sexual stimuli? Studies of women's T responses to visual sexual stimuli have used pornographic films chosen by researchers, so the actors in the films may rarely match participants' individual preferences for attractiveness. Alternatively, pornography may not contain any true cues to partner quality at all, given that the stereotyped and scripted nature of the interactions prohibits any evaluation of an individual's behavior. Perhaps even imagining a self-defined attractive partner, as in the sexual thoughts study (Goldey and van Anders 2011), is a stronger stimulus for women's T than watching sexual interactions between unknown actors who are highly unlikely to ever be potential partners. In support of the hypothesis that cues to partner quality predict $\Delta \mathrm{T}$, heterosexual women's T responses to films of 'courtship' interactions were positively correlated with their ratings of the physical and behavioral attractiveness of the man in the film (Lopez et al. 2009). Thus, findings from research with birds suggest novel insights about the potential role of cues to partner quality in women's $T$ responses.

Although aggression and competition have received more attention than sexuality in studies of social behavior and androgens in birds (Goymann et al. 2007), research points to a role for sexual cues in modulation of T. For male birds, effects of sexual stimuli on $\mathrm{T}$ are especially strong in socially monogamous, biparental species. It is clear that stimuli and behaviors of a partner drive $\mathrm{T}$ release in females and males; to what extent copulation itself contributes to $\Delta \mathrm{T}$ is more ambiguous. Research in birds could prove fruitful for investigating how $\mathrm{T}$ is linked with sexuality decoupled from reproduction, as pair bonded individuals of some species engage in non-conceptive sexual interactions outside of the breeding season, which may function in pair bond maintenance (for an example, see Kellam et al. 2004). Additionally, a number of bird species demonstrate same-sex sexual behavior. In zebra finches, for example, female-female and male-male pair bonds are similar to female-male pair bonds in terms of the 
characteristics and frequencies of sexual and affiliative behaviors (Elie et al. 2011). Research with zebra finches has made essential contributions to behavioral neuroendocrinology via hormone manipulation studies, and perhaps this species could also serve as a useful model for studying hormone responses to same- and other-sex sexual interactions. Sexuality has typically been defined as male-female interactions during the breeding season in studies of $\Delta \mathrm{T}$, but broadening this definition would clarify whether $\Delta \mathrm{T}$ is actually specific to these contexts.

\section{Sexual Modulation of Androgens in Fish}

Like birds, teleost fish, and especially cichlid fish, are model organisms for studying hormone-behavior relationships due to the diversity of mating and parenting systems across species (Oliveira 2009). Furthermore, many species of fish show extreme plasticity of behavior (e.g., sex-changing) in response to environmental cues, and fish are relatively easy to keep in a laboratory (Oliveira 2009). Teleosts provide a prime example of the complexity of defining sexuality; most species fertilize externally and some key elements of sexual behavior in other vertebrates (e.g., mounting) are less relevant or irrelevant for teleosts. Yet, teleosts display distinct patterns of courtship behavior that vary across species but often include color changes, pheromone release, vocalizations, or motor patterns (Gonçalves and Oliveira 2010). Examples of motor patterns include dancing in a zigzag formation in male sticklebacks, chasing and nudging behavior in male goldfish, and swimming up and down in female straightnose pipefish (Gonçalves and Oliveira 2010; Munakata and Kobayashi 2010). Although courtship displays are more commonly performed by males, in some species, particularly those with high paternal investment, females display to compete for males (reviewed in Gonçalves and Oliveira 2010). Courtship displays typically culminate in the release of eggs and sperm, or spawning. Like displays, methods of spawning vary between species but may involve behaviors such as body quivering or tail flipping (to mix eggs and sperm) (reviewed in Gonçalves and Oliveira 2010; Munakata and Kobayashi 2010).

Research with teleost fish has been essential in demonstrating that androgens are responsive to sexual behavior. This work has focused on both T and 11-ketotestosterone (11-KT), which is considered the most active androgen in male teleosts (Borg 1994). Whereas T levels are generally similar between females and males, 11-KT is typically higher in males (Borg 1994). 11-KT increases in response to female cues, courtship interactions, or spawning in males of some cichlids, but $\mathrm{T}$ responds less consistently (Hirschenhauser et al. 2004; Kidd et al. 2013; O’Connell et al. 2013; Sessa et al. 2013). In the cichlid Oreochromis mossambicus, the frequency of courtship behaviors in males was more strongly linked with their 11-KT after the interaction than before, which could indicate that courtship behavior increased 11-KT, that changes in 11-KT rapidly modulated courtship behavior, or both, highlighting the potential for bidirectional androgen-behavior links (Borges et al. 1998). Some of the few studies with females have shown elevated $\mathrm{T}$ prior to and during spawning in gilthead seabream (Jerez et al. 2006) and a peak in $\mathrm{T}$ four days prior to spawning in African cichlids (Kidd et al. 2013). In female rainbow trout, an increase in $T$ clearly precedes ovulation and spawning, but whether a male is present seems to have little effect on $\mathrm{T}$ in ovulating 
females (Liley et al. 1986). While T shows fluctuations linked with reproductive cycles in female fish, the extent to which females' $T$ is responsive to sexual cues remains open, but important; this research could highlight whether females' $\mathrm{T}$ might respond to cues indicative of partner quality in taxa besides birds, or if other factors are more essential for $\Delta \mathrm{T}$ in female fish.

Beyond providing evidence that sexual modulation of androgens occurs, work with teleosts demonstrates nuances in androgen responses to sexual stimuli. Specifically, androgen responses vary based on a species' parenting system, the types of sensory stimuli present, and the social context prior to the sexual encounter. In an elegant comparative study of males from five species of cichlids, Hirschenhauser et al. (2004) found that only the three non-paternal species showed an increase in 11-KT after a 4-h interaction with an ovulating female. Mating system was a less clear predictor, as neither of the two biparental species showed an 11-KT response to a female, despite varying in mating system (monogamous vs. polygynous). This finding suggests some deviation from birds, where monogamous, biparental species tend to show stronger $\Delta \mathrm{T}$ (see Sexual Modulation of $\mathrm{T}$ in Rodents for further discussion of this point).

The specific sensory cues necessary and sufficient for androgen responses to sexual contexts may be a function of a species' typical environment. In the African cichlid, a polygynous, lekking species with exclusive maternal care, visual cues are especially important. When males were presented with either visual cues from a receptive female through a transparent divider, chemical cues via a female pheromone, or both visual and chemical cues simultaneously, only the visual cues alone increased $\mathrm{T}$ compared to a control condition (O'Connell et al. 2013). Because the African cichlid breeds continuously and chemical cues from receptive females are always present in natural environments, it may be adaptive for males to reserve androgen responses for when a female is in visual proximity (O'Connell et al. 2013). It is unclear why a combination of visual and chemical cues failed to elicit an androgen response, even though it elicited courtship displays; this suggests some dissociation of behavioral and hormonal responses in this species (O’Connell et al. 2013) - as discussed earlier for humans, non-human primates, and birds. Investigations of whether chemical cues elicit androgen responses in species where females and males are more widely distributed or when there are time-delimited breeding phases would fill gaps in current understandings of androgen responses to different sensory modalities.

In addition to parenting system and varying importance of sensory modalities, the social context immediately prior to a sexual interaction modulates androgen responses. After a period of social isolation, exposure to a female increased $11-\mathrm{KT}$ in male Oreochromis mossambicus (Hirschenhauser et al. 2004). In contrast, exposure to females decreased $\mathrm{T}$ and 11-KT after males of the same species spent several days in all-male groups (Oliveira et al. 1996). These findings raise the question of what represents a meaningful 'baseline' to compare with responses to sexual stimuli. In a non-laboratory environment, sexual interactions are likely preceded by a number of other affiliative or agonistic interactions, and it follows that if androgens are already elevated (e.g., because of territorial conflicts), sexual encounters may not increase them further, or could actually elicit an apparent decrease in androgens. Competition and mating-relevant stimuli interact to affect $\mathrm{T}$ in humans as well, albeit in a different pattern. One study suggests additive effects of social stimuli, such that $\mathrm{T}$ was higher in 
women and men after an athletic competition when there was a higher ratio of other-sex individuals present (Miller et al. 2012).

In addition to showing that androgen responses to sexual stimuli are sensitive to social context, research with fish provides insight into the downstream consequences of these responses. Any effects of androgen responses on behavior are likely context-dependent, given that fish androgens increase in response to sexual interactions and territorial challenges, despite vastly different behaviors displayed in each (Hirschenhauser et al. 2004; O'Connell et al. 2013; Sessa et al. 2013). In male goldfish, contact with preovulatory females increases T (Kobayashi et al. 1986), and T administration rapidly increases approach behavior toward visual cues from a female (Lord et al. 2009). Taken together, these results suggest that androgen responses to sexual stimuli could facilitate sensitivity or orientation toward visual sexual cues (Lord et al. 2009), and this interpretation is consistent with the finding in cichlids that visual cues are necessary for sexually-stimulated androgen responses (O'Connell et al. 2013). These findings parallel results in humans linking T with interest in visual sexual or mating-relevant stimuli. For example, men with higher $\mathrm{T}$ view visual sexual stimuli longer (Rupp and Wallen 2007), and women and men show an increased preference for facial masculinity and femininity, respectively, when their T is high (Welling et al. 2007, 2008). Interestingly, winning a competition, which has been shown to increase men's $T$ (van Anders and Watson 2006), also increases men's preferences for femininity in women's faces (Welling et al. 2013). Thus, one function of $\mathrm{T}$ responses to competitive and/or sexual interactions could be to influence attention to visual sexual stimuli or visual cues relevant to mate choice.

Research with African cichlids suggests that an individual's androgen response could additionally have implications for their potential partners' mate choice. When given the option to spawn with males of different sizes, female cichlids spawned with the larger male except when the smaller male released equivalent $\mathrm{T}$ to the larger male on the day of spawning (Kidd et al. 2013). On days when not spawning, females generally preferred to spend time with smaller males, who are less aggressive (Kidd et al. 2013). Whether males' T responses shape female choice or whether females' behavior (e.g., solicitations, proximity) influences males' $\mathrm{T}$, or both, is an exciting question for future studies, as the answer would help clarify the (bi)directionality of T-sexuality links in this species.

In sum, research with teleost fish echoes findings from other taxa that while androgens are highly responsive to sexual stimuli, the species-specific environmental context of the sexual interaction modulates androgen responses. Future research is needed to characterize androgen responses to sexual interactions in female fish, and the diversity of sexual behaviors and social systems among teleosts (e.g., female vs. male-initiated courtship; maternal vs. paternal vs. biparental care) provides an ample base to explore predictors of androgen responses in females. Finally, teleosts could serve as ideal models for studying how individuals' own behaviors versus cues from potential mates (which seem important for birds and primates) shape androgen responses, and in turn, whether androgen responses affect individual sexual behavior, a potential partner's mate choice, or both.

\section{Sexual Modulation of $\mathbf{T}$ in Rodents}

Sexually-stimulated $\mathrm{T}$ responses have been extensively investigated in laboratory paradigms with rodents. We provide an overview of the properties of $\Delta \mathrm{T}$ in male 
house mice and rats (see Gleason et al. 2009 and Nyby 2008 for more detailed reviews), and then focus on potential open questions in naturalistic paradigms and with other rodent species.

Male house mice and rats show a spike in LH followed by a rise in T shortly after encountering a novel female and again following ejaculation (Gleason et al. 2009; Nyby 2008). Tactile contact is not required for $\Delta \mathrm{T}$, as males show $\mathrm{LH}$ and/or $\mathrm{T}$ responses when separated from a receptive female by a partition (Amstislavskaya and Khrapova 2002; Amstislavskaya and Popova 2004; Amstislavskaya et al. 2013; Bonilla-Jaime et al. 2006) and even to female urine alone (Clancy et al. 1988; Coquelin and Bronson 1980; James et al. 2006). These findings raise the question of whether pheromones - which are present in all of these situations - are the primary stimulus driving $\Delta \mathrm{T}$ in male mice and rats. However, while removal of the vomeronasal organ in male mice blocked LH responses to female urine, LH still responded to an interaction with a female, suggesting that visual and/or auditory components of female behavior can compensate for the lack of pheromonal stimuli (Coquelin et al. 1984). Thus, pheromonal stimuli may be sufficient but not necessary for $\Delta \mathrm{T}$ in male rodents (see also Nyby 2008).

Social cues and prior experiences modulate $\Delta \mathrm{T}$ in male rats and house mice. Previous sexual experience potentiates $\Delta \mathrm{T}$ in male rats (Bonilla-Jaime et al. 2006; Kamel et al. 1975, 1977), and - consistent with findings that anticipating sexual activity increases T in humans (Anonymous 1970; Hamilton and Meston 2010; van Anders et al. 2007) - male rats' $T$ also responds to initially neutral stimuli associated with sexual encounters (e.g., a testing arena, a neutral odor) (Graham and Desjardins 1980; Kamel et al. 1975). A novel female is a stronger stimulus for androgens than a female the male has interacted with previously (Coquelin and Bronson 1979), but the importance of the female's sexual receptivity is less clear (Amstislavskaya and Popova 2004; Bonilla-Jaime et al. 2006; Coquelin and Bronson 1979, 1980). Early life experiences can affect $\Delta \mathrm{T}$, such that male rats who were socially isolated during peri-adolescence do not show $\Delta \mathrm{T}$ (Amstislavskaya et al. 2013). Finally, cues from conspecific males can also modulate $\Delta \mathrm{T}$. The presence of other males' urine completely suppresses LH responses to female urine in male mice (Clancy et al. 1988), suggesting that competitors may be able to block each others' hormonal responses. Missing from the current picture is whether this effect is moderated by rank or social status; for example, might an individual still mount a $\mathrm{T}$ response in the presence of a competitor of a lower rank, but not when an individual of higher rank is present?

The extent to which the properties of $\Delta \mathrm{T}$ elucidated in these studies apply to more naturalistic sexual conditions remains an open question. Under naturalistic conditions, a female rat controls the timing of sexual stimulations through a series of approaches and withdrawals from the male rat (McClintock and Adler 1978); this behavior is known as pacing. Vaginocervical stimulation regulates hormonal changes required for pregnancy in the female rat, and pacing optimizes the timing of stimulation such that these changes can occur with fewer intromissions (reviewed in Erskine et al. 2004). Female house mice also display pacing behavior when given the opportunity to withdraw from a male in laboratory contexts, though it is unknown whether this is the case in the wild (Johansen et al. 2008). In standard laboratory test cages - like those used in studies of copulation and $\Delta \mathrm{T}$ in male rodents (Bonilla-Jaime et al. 2006; Coquelin and 
Bronson 1980; Kamel et al. 1975, 1977) - female rodents do not have room to withdraw from the male and thus cannot pace their sexual stimulations.

Interestingly, female and male rats only form conditioned place preferences (CPP) for locations where they have mated when they are able to control the timing of sexual stimulations (Martinez and Paredes 2001). That is, female rats show CPP only when they can pace, and males show CPP only when sexual behavior occurs in a standard test cage (Martinez and Paredes 2001). Notably, T administration alone induces CPP (for review, see Wood 2004), though effects of T and its metabolites on CPP are more mixed in females than males (de Beun et al. 1992; Jorge et al. 2005). This begs the question of whether $\Delta \mathrm{T}$ mediates preferences for locations where mating has occurred (Gleason et al. 2009; Nyby 2008), and if control of the rate of sexual stimulation is required for this effect. In the wild, female and male rats mate with multiple partners within the same time frame (McClintock et al. 1982), such that both female and male rats may be able to achieve their ideal pattern of stimulation (Martinez and Paredes 2001). Thus, even paced mating in a laboratory context is quite different from naturalistic conditions. Could the way sexuality is operationalized in the laboratory affect $\Delta \mathrm{T}$ ? To our knowledge, whether $\Delta \mathrm{T}$ occurs in female rodents is unknown, and examining how contexts varying in the potential for controlling sexual stimulation (e.g., standard test cage, pacing, group mating) affect $\Delta \mathrm{T}$ in male and female rodents would help clarify a potential role for $\mathrm{T}$ in CPP.

Studies with rodent species other than house mice and rats, while less numerous, have provided insights about the role of $\Delta \mathrm{T}$ in species with varied mating systems. In the monogamous, biparental California mouse (Peromyscus californicus), males' $\mathrm{T}$ following a one-hour courtship interaction (which included behaviors like following, sniffing, wrestling, and chasing, but not copulation) was higher on average than T while parenting, but not significantly different from a baseline (pre-courtship) $\mathrm{T}$ measure (Gleason and Marler 2010). However, males' T responses to courtship were highly variable $-53 \%$ of males showed a decrease in $\mathrm{T}$ in response to courtship, while the remaining $47 \%$ showed an increase - and this variation predicted paternal quality, such that males with a higher $\Delta \mathrm{T}$ later displayed reduced latency to approach pups and increased huddling (Gleason and Marler 2010). In a follow-up study, the authors investigated whether female California mice might use males' $\Delta \mathrm{T}$ as a signal to choose mates who provide better quality paternal care. Unexpectedly, males' $\Delta \mathrm{T}$ did not predict either female preference or reproductive success; instead, results suggested that biological or behavioral compatibility of the pair might be a better predictor of reproductive success in this biparental species (Gleason et al. 2012).

In another monogamous Peromyscus species (Peromyscus aztecus), housing with a female for eight days significantly increased males' $T$ compared to being housed individually (Demas and Nelson 1998). Although copulation occurred within 2-4 days of cohabitation, it was unclear whether sexual behavior increased $\mathrm{T}$ or stress from social isolation decreased $\mathrm{T}$ in the comparison condition (Demas and Nelson 1998). In male polygynous white-footed mice (Peromyscus leucopus), long-term housing with a female elevated $\mathrm{T}$, but only for those kept on long day photoperiods, indicating seasonal cues are relevant in this species (Pyter et al. 2005). Thus, clear differences in $\Delta \mathrm{T}$ between Peromyscus species based on mating system have not yet emerged from current research. 
Across taxa, findings point to some inconsistencies regarding effects of mating and parenting systems on $\Delta \mathrm{T}$. In fish, $\Delta \mathrm{T}$ appears strongest in non-paternal species regardless of mating system, whereas in birds, $\Delta \mathrm{T}$ is strongest in monogamous, biparental species, and in rodents and primates, effects are mixed. Do monogamous, biparental species show high $\Delta \mathrm{T}$ because their $\mathrm{T}$ has more 'room' to respond to social stimuli, or, do they show low $\Delta \mathrm{T}$ because sexual interactions may have nurturant functions (e.g., pair bond formation, coordination of offspring care) and $\Delta \mathrm{T}$ may interfere with these nurturant behaviors? Our review suggests both of these predictions may be overly simplistic. Perhaps the specific stimuli that cue $\Delta \mathrm{T}$ vary by mating or parenting system; for example, pair compatibility or a partner's behavior may be more important for $\Delta \mathrm{T}$ when partners must coordinate parental care. Indeed, previous authors have suggested this may be why a female partner's hormonal state is more important for $\Delta \mathrm{T}$ in males of biparental bird species than in male house mice or rats (Moore 1983). Additionally, T responses to certain types of sexual cues (e.g., from novel individuals) may vary based on a combination of a species' mating or parenting system and an individual's current pair bond or parenting status (Ziegler et al. 2005). And, meta-analytic work indicates mating and parenting system may not affect $\Delta \mathrm{T}$ the same way in all vertebrate taxa, and that overall, parenting system may be more important than mating system for $\Delta \mathrm{T}$ (Hirschenhauser and Oliveira 2006).

As a whole, research with rodent models has greatly contributed to knowledge of the specific sensory cues required for $\Delta \mathrm{T}$ and how previous experience modulates $\Delta \mathrm{T}$. Effects of $\mathrm{T}$ administration on conditioned place preference imply a role for $\Delta \mathrm{T}$ in $\mathrm{CPP}$ that remains to be clarified by future research, especially research involving naturalistic sexual contexts. Finally, research in Peromyscus species seems promising for comparing closely related species with different mating systems, as well as examining how $\mathrm{T}$ responds to sexual activity in different stages of pair bonding (e.g., Is $\Delta \mathrm{T}$ to copulation the same during earlier stages of pair bond formation vs. later maintenance? Is it equally predictive of paternal quality at both stages?).

\section{Cross-Species Synthesis}

Our review demonstrates broad evidence for sexual modulation of androgens across fish, birds, rodents, and primates, despite the diversity of sexual behaviors between and within these taxa. Clearly, $\mathrm{T}$ does not just affect sexual behavior, but responds dynamically to sexual contexts, and this response appears to be conserved across at least some vertebrate taxa. However, in addition to the pervasiveness of sexual modulation of $\mathrm{T}$, our review also highlights its variability. $\Delta \mathrm{T}$ does not occur to the same degree in every species, individual, or sexual situation and instead appears to be sensitive to context-specific parameters. Here, we discuss overarching patterns in research on $\Delta \mathrm{T}$ thus far and questions that remain for future research.

\section{What Drives $\Delta \mathrm{T}$ ?}

If $\Delta \mathrm{T}$ is variable, what factors predict when and to what magnitude a $\mathrm{T}$ response will occur? Overall, the body of research on $\Delta \mathrm{T}$ thus far suggests several broad conclusions: 
1) Specific sensory stimuli may be less important than the context in which they occur. While some findings do suggest that particular sensory modalities are required for $\Delta \mathrm{T}$ in some species (e.g., auditory cues in ring doves and visual cues in African cichlids), overall, the social context surrounding a sexual stimulus seems to be more important than specific sensory cues. This is particularly true for primates, including humans, where $\Delta \mathrm{T}$ is sensitive to the content of sexual thoughts or knowledge of the source of olfactory cues. Even in rodents, it seems that $\Delta \mathrm{T}$ can compensate for the absence of some cues (e.g., pheromones) when others are present, and that factors such as prior sexual experiences or the presence of potential competitors take precedence. The same sexual stimulus can elicit different $T$ responses based on context, as evidenced by the effects of social housing conditions on $\Delta \mathrm{T}$ in male marmosets and cichlid fish. The ability to adjust $\Delta \mathrm{T}$ based on context, rather than to mount $\Delta \mathrm{T}$ automatically in response to particular sensory modalities, may be adaptive in balancing costs and benefits of $\mathrm{T}$. Prior experiences with a specific partner, presence of competitors, or location may be more accurate predictors than sensory stimulus modalities of whether pursuing a sexual encounter will be costly or beneficial, and thus whether a $T$ response is worthwhile.

2) $\Delta T$ can occur even in the absence of behavioral changes and vice versa. Although specific sensory cues rarely seem to drive $\Delta \mathrm{T}$, behavioral responses do not seem to be required either. This is exemplified by $\Delta T$ 's responsivity to sexual cues in the absence of sexual behavior (e.g., sexual thoughts, olfactory cues, a partner behind a partition, etc.) and to a partner's solicitations in the absence of any behavioral response (Lynch et al. 2002; Pinxten et al. 2003). These findings are consistent with research showing that viewing a competitive interaction without participating is sufficient to increase androgens (reviewed in Oliveira 2009) and demonstrate that T may be responding, at least partially, to cues signaling interest from a potential sexual partner. This possibility raises interesting questions for investigation: in humans especially, is the perception of a partner's arousal or pleasure important for $\Delta \mathrm{T}$ ? To what extent would $\Delta \mathrm{T}$ be linked with an individual's perceptions of their partner's arousal or pleasure versus their partner's actual arousal or pleasure?

The reverse also seems to be true: changes in sexual arousal and behavior can occur in the absence of $\Delta \mathrm{T}$, as evidenced by the presence of courtship displays in conditions that did not change $\mathrm{T}$ in African cichlids (O'Connell et al. 2013) and behavioral and arousal responses in strains of mice that do not show $\Delta \mathrm{T}$ (Amstislavskaya and Khrapova 2002; James et al. 2006). This suggests $T$ responses are not essential for sexual behavior or arousal, at least in some species (Gleason et al. 2009). An important caveat is that $\Delta \mathrm{T}$ and behavior may be more strongly coupled in some species, individuals, or contexts than others. Research on $\mathrm{T}$ and pair bonding has highlighted the importance of moderator variables like extra-pair sexual interest and desire for new partners, such that pair bonding and $\mathrm{T}$ are linked in some individuals but not others (Edelstein et al. 2011; McIntyre et al. 2006; van Anders and Goldey 2010). The same may be true for $\Delta \mathrm{T}$, and indeed, $\Delta \mathrm{T}$ and behavior $d o$ seem to be linked in humans in contexts that provide an opportunity for a behavioral response, such as 'courtship' conversations with a potential partner, as opposed to viewing pornography in the lab. This pattern of findings could also reflect a stronger role for $\Delta \mathrm{T}$ in facilitating courtship or sexual competition than the mechanics of sexual arousal and behavior (Gleason et al. 2009; Nyby 2008; Roney et al. 2010). 
3) It's not all about aggression. Research in all taxa reviewed, but especially birds and primates, suggests that apparent associations between sexuality and $\mathrm{T}$ may sometimes be secondary to links between $\mathrm{T}$ and aggression, sexual competition, or dominance rank. Relatedly, sexual stimuli may increase $\mathrm{T}$ because they are cues that competition for sexual partners is likely to occur. Yet, we should be cautious of discounting the contribution of sexuality - independent of aggression - to patterns of $\mathrm{T}$ release. Findings in birds clearly show that female sexual behavior affects $\mathrm{T}$ in males and vice versa, even in situations where potential competitors are absent. Likewise, while aggression did explain links between sexuality and $\mathrm{T}$ in many primate species, tufted capuchins were an exception, perhaps because females initiate sexual behavior in this species. These results indicate that aggression and sexuality both contribute to $\mathrm{T}$ profiles, but more work is needed to clearly dissociate their potential additive contributions. And, considering competition can be helpful in predicting when sexual stimuli will increase $\mathrm{T}$; interactions perceived or experienced as competitive (e.g., sexual activity with unfamiliar partners in men) may increase $\mathrm{T}$ compared to those perceived or experienced as nurturant (van Anders 2013).

The prediction that sexual contexts intertwined with aggression or competition increase $\mathrm{T}$ largely received support across species, but what about the prediction that nurturant sexual contexts decrease T (van Anders 2013)? Sexual interactions within a pair bond increased $\mathrm{T}$ in several bird species, some Peromyscus species (with large individual differences), and in humans, where most studies of T responses to sexual activity involved individuals in committed, romantic relationships. Perhaps caution is warranted in assuming that all sexual interactions within a pair bond are nurturant (and that those outside of a pair bond are not). In some contexts, sexuality within pair bonds could be primarily oriented around genital/erotic pleasure, limiting a partner's sexual access to others, or (especially in early stages of pair bond formation) displaying to attract the partner. Thus, pair bonding status could be a less accurate metric of nurturance than parameters like huddling or grooming before or after sexual interactions.

Nurturance may take different forms in different species, such that there may be no universal definition of nurturant sexual behaviors (van Anders et al. 2011). Similarly, erotic pleasure, which has been predicted to increase T (van Anders 2013), can be challenging to define in humans and other species. Is erotic pleasure a meaningful or observable construct in fish? What about in female tufted capuchins, who sometimes emit characteristic squeals during mounting, or engage in mounting accompanied by playful behavior (Carosi and Visalberghi 2002)? Asking whether vocalizations or play during mounting might correlate with $\Delta \mathrm{T}$ could provide one starting point for ascertaining the role of genital/erotic pleasure in $\Delta \mathrm{T}$ across species.

4) Many factors interact to maximize $\Delta T$ when it is most beneficial and limit $\Delta T$ when it is most costly. Perhaps the most consistent finding with regards to $\Delta \mathrm{T}$ is its variation, and this variation in $\Delta \mathrm{T}$ may be adaptive. Fine-tuning $\mathrm{T}$ expression allows individuals to balance the costs and benefits of $\mathrm{T}$, and, to the extent that $\Delta \mathrm{T}$ facilitates current or future sexual interactions, modulating $\Delta \mathrm{T}$ could provide a mechanism for adjusting behavior to the potential benefits and risks of a given sexual context.

Several pieces of evidence suggest $\Delta \mathrm{T}$ occurs most strongly in individuals who are more likely to benefit from $\mathrm{T}$ release and less likely to incur costs. A relatively 
consistent finding across species, especially in rodents, is that prior sexual experience increases $\Delta \mathrm{T}$. Learned associations from previous experiences may increase the likelihood of $\Delta \mathrm{T}$ translating into a behavioral response. Evidence from humans suggests that individuals who could be especially vulnerable to physiological costs of $\Delta \mathrm{T}$, as indexed by higher cortisol levels, have lower $\Delta \mathrm{T}$ (Roney et al. 2010). How $\Delta \mathrm{T}$ responds to energy deficits or immune challenges remains a fruitful area for future research, and tradeoffs between $\Delta \mathrm{T}$ and energetic or immune demands would support the hypothesis that variation in $\Delta \mathrm{T}$ offsets physiological costs of $\mathrm{T}$.

$\Delta \mathrm{T}$ is also sensitive to situational factors and partner cues in ways that suggest adaptive fine-tuning of this response. For example, female birds' and women's $\Delta \mathrm{T}$ appears sensitive to partner quality, and variation in $\Delta \mathrm{T}$ could modulate the reward value of specific partners and the likelihood of engaging in (or repeating) sexual activity with that partner. $\Delta \mathrm{T}$ 's sensitivity to solicitations from partners could preempt T expression when sexual activity is unlikely or pair compatibility is low. Notably, however, situational factors do not seem to have the same effects in all individuals or species, suggesting interactive effects. Partner novelty generally increases $\Delta \mathrm{T}$, which could help overcome anxiety - but $\Delta \mathrm{T}$ to novel partner cues may be inhibited in pair bonded individuals (Ziegler et al. 2005) (perhaps especially in species where extra-pair mating decreases fitness). Similarly, $\Delta T$ 's effects should be especially advantageous in situations involving sexual competition, and overall, evidence supports a positive link between sexual competition and $\Delta \mathrm{T}$. Yet, one rodent study showed that cues from competitors suppress androgen responses (Clancy et al. 1988), and a study in humans also found no effect of the presence of a potential competitor on men's $\Delta \mathrm{T}$ (Roney et al. 2010). One possibility is that $\Delta \mathrm{T}$ in the presence of competitors may depend on the relative ranks or status of those involved and/or the ability of an individual to incur energetic costs of higher $\Delta \mathrm{T}$.

Finally, the effects of individual and situational factors on $\Delta \mathrm{T}$ are embedded in a species-specific backdrop that includes a species' mating, parenting, and social systems and resulting species-specific contexts of sexual behavior (e.g., group mating in rats, female initiation in tufted capuchins). The most important individual and situational factors for $\Delta \mathrm{T}$ likely vary by species, such that, for example, pair compatibility may be less relevant in species that do not form long-term pair bonds, and relationships between a potential partner and other individuals may only be important for species like humans where social alliances are key to fitness. In Fig. 2, we summarize predictions about the effects of individual and situational factors on $\Delta T$ (including some interactive effects) based on empirical findings from across species and the tradeoffs involved in $\mathrm{T}$ release. These predictions are intended to provide a starting point for understanding how individual and situational factors affect $\Delta \mathrm{T}$ across species, and future work will likely add nuance to the predictions we make here.

\section{Future Directions and Summary}

Hormone responses are typically understood to feed back on behavior in an iterative fashion, and the findings in this review suggest a wide range of potential functions for 


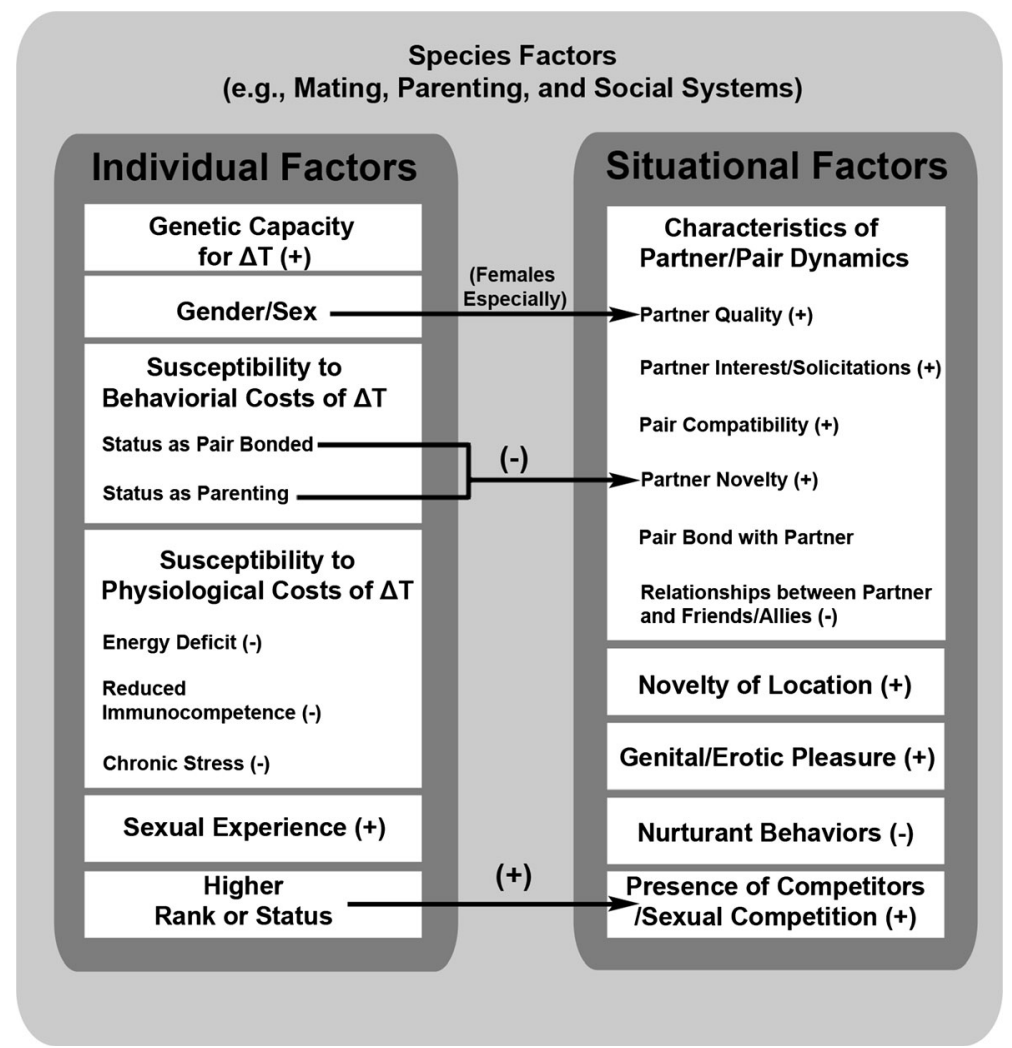

Fig. 2 Hypothesized effects of individual and situational factors on sexually-modulated testosterone $(\Delta \mathrm{T}) .(+)$ indicates the factor is expected to increase $\Delta \mathrm{T}$, and $(-)$ indicates the factor is expected to decrease $\Delta \mathrm{T}$ (factors without $\mathrm{a}+$ or - have unclear effects). Effects of individual and situational factors on $\Delta \mathrm{T}$ occur against a backdrop of species-specific factors, so hypothesized effects represent overarching patterns but may not be consistent across all species

$\Delta \mathrm{T}$, including facilitating approach or orientation toward sexual cues, signaling to or evaluating a potential partner, coordinating behavior within a bonded pair, or promoting learning or reward mechanisms associated with sexuality. Evaluating these hypothesized functions for $\Delta \mathrm{T}$ in more detail, and the extent to which functions of $\Delta \mathrm{T}$ are context or species-specific (Gleason et al. 2009), remains a challenge for future comparative work.

Our review was not intended to be exhaustive but instead reflects patterns and thus also gaps in the literature. We have not addressed amphibians, reptiles, or mammals besides rodents and primates, as $\Delta \mathrm{T}$ is less commonly studied in these groups. Attention to species with unique social systems - such as the female-dominant spotted hyena - could yield interesting insights for social modulation of $\Delta \mathrm{T}$. Perhaps the largest gap is the lack of data on $\Delta \mathrm{T}$ in non-human females. Research in humans suggests that the overarching social role of $\mathrm{T}$ is similar in women and men, with some nuances by gender/sex in how T responds to social context (van Anders et al. 2011; van Anders 2013). And, research in birds implicates $T$ in life-history tradeoffs in females as well as males (Ketterson et al. 2005). Because many of the conclusions in this review are drawn mainly from existing data on males, it cannot be assumed that the patterns will generalize to females, nor that they will necessarily differ. 
Broadening definitions of what counts as sexual would expand our knowledge of $\Delta \mathrm{T}$. To our knowledge, no research has examined how $\mathrm{T}$ responds to same-sex sexual interactions. In female Japanese macaques, same-sex consortship activity varies across the ovarian cycle, suggesting a hormonal component motivating this behavior (Vasey 2006); would hormones respond to same-sex consortships as well? Examining $\mathrm{T}$ responses to female-female versus female-male consortships could be one means of evaluating the hypothesis that female-female mounting evolved as a by-product of female-male mounting in this species (Vasey 2006). Finally, examining $\Delta \mathrm{T}$ in a greater variety of behavioral paradigms, such as paced mating in rats, could spark new questions about the role of the sexual context in shaping $\Delta \mathrm{T}$.

$\mathrm{T}$ and other androgens respond to sexual cues and behaviors in a wide range of vertebrate species. The effects of sexuality on $\mathrm{T}$ across species demonstrate the malleability of androgens in response to the social environment; not only does sexual behavior modulate $\mathrm{T}$, but a milieu of species, individual, and situational factors in turn modulate the extent of sexuality's effect on T. Sexually-stimulated T responses may provide a mechanism by which individuals can adjust their behavior in response to an array of potential sexual opportunities. We hope our cross-species synthesis poses new questions for research on sexual modulation of $\mathrm{T}$, especially with understudied species, genders/sexes, and sexual contexts.

Acknowledgments K.L.G. was supported by a National Science Foundation Graduate Research Fellowship (grant no. DGE0718128).

Ethical Standards The manuscript does not contain clinical studies or patient data.

Conflict of Interest The authors declare that they have no conflict of interest.

\section{References}

Abramson, P. R., \& Pinkerton, S. D. (2002). With pleasure: Thoughts on the nature of human sexuality. New York: Oxford University Press.

Adkins-Regan, E. (2009). Neuroendocrinology of social behavior. Institute for Laboratory Animal Research Journal, 50(1), 5-14.

Adkins-Regan, E. (2012). Hormonal organization and activation: Evolutionary implications and questions. General and Comparative Endocrinology, 176(3), 279-285.

Adkins-Regan, E., \& Leung, C. H. (2006). Hormonal and social modulation of cloacal muscle activity in female Japanese quail. Physiology \& Behavior, 87(1), 82-87.

Alfaro, J. W. (2005). Male mating strategies and reproductive constraints in a group of wild tufted capuchin monkeys (Cebus apella nigritus). American Journal of Primatology, 67(3), 313-328.

Amstislavskaya, T. G., \& Khrapova, M. V. (2002). Effect of genotype on behavioral and hormonal components of sexual activation of male mice. Bulletin of Experimental Biology and Medicine, 133(5), 475-477.

Amstislavskaya, T. G., \& Popova, N. K. (2004). Female-induced sexual arousal in male mice and rats: Behavioral and testosterone response. Hormones and Behavior, 46(5), 544-550.

Amstislavskaya, T. G., Bulygina, V. V., Tikhonova, M. A., \& Maslova, L. N. (2013). Social isolation during peri-adolescence or adulthood: Effects on sexual motivation, testosterone and corticosterone response under conditions of sexual arousal in male rats. The Chinese Journal of Physiology, 56(1), 36-43. 
Anonymous (1970). Effects of sexual activity on beard growth in man. Nature, 226, 869-870.

Bagemihl, B. (1999). Biological exuberance: Animal homosexuality and natural diversity. New York: St. Martin's Press.

Bailey, N. W., \& Zuk, M. (2009). Same-sex sexual behavior and evolution. Trends in Ecology \& Evolution, 24(8), 439-446.

Beehner, J., Bergman, T., Cheney, D., Seyfarth, R., \& Whitten, P. (2006). Testosterone predicts future dominance rank and mating activity among male chacma baboons. Behavioral Ecology and Sociobiology, 59(4), 469-479.

Bernstein, I. S., Rose, R. M., \& Gordon, T. P. (1977). Behavioural and hormonal responses of male rhesus monkeys introduced to females in the breeding and non-breeding seasons. Animal Behaviour, 25(3), 609614.

Bonilla-Jaime, H., Vazquez-Palacios, G., Arteaga-Silva, M., \& Retana-Marquez, S. (2006). Hormonal responses to different sexually related conditions in male rats. Hormones and Behavior, 49(3), 376-382.

Borg, B. (1994). Androgens in teleost fishes. Comparative Biochemistry and Physiology, 109(3), 219-245.

Borges, R. A., Oliveira, R. F., Almada, V. C., \& Canário, A. V. (1998). Short-term social modulation of 11ketotestosterone levels in males of the cichlid fish Oreochromis mossambicus during male-female interactions. Acta Ethologica, 1(1-2), 43-48.

Bribiescas, R. G. (2001). Reproductive ecology and life history of the human male. American Journal of Physical Anthropology, Suppl, 33, 148-176.

Carani, C., Bancroft, J., Del Rio, G., Granata, A. R., Facchinetti, F., \& Marrama, P. (1990). The endocrine effects of visual erotic stimuli in normal men. Psychoneuroendocrinology, 15(3), 207-216.

Carosi, M., \& Visalberghi, E. (2002). Analysis of tufted capuchin (Cebus apella) courtship and sexual behavior repertoire: Changes throughout the female cycle and female interindividual differences. American Journal of Physical Anthropology, 118(1), 11-24.

Cavigelli, S. A., \& Pereira, M. E. (2000). Mating season aggression and fecal testosterone levels in male ringtailed lemurs (Lemur catta). Hormones and Behavior, 37(3), 246-255.

Cerda-Molina, A. L., Hernandez-Lopez, L., Chavira, R., Cardenas, M., Paez-Ponce, D., Cervantes-De la Luz, H., et al. (2006). Endocrine changes in male stumptailed macaques (Macaca arctoides) as a response to odor stimulation with vaginal secretions. Hormones and Behavior, 49(1), 81-87.

Cerda-Molina, A. L., Hernandez-Lopez, L., de la O, C. E., Chavira-Ramirez, R., \& Mondragon-Ceballos, R. (2013). Changes in men's salivary testosterone and cortisol levels, and in sexual desire after smelling female axillary and vulvar scents. Frontiers in Endocrinology, 4, article 159.

Chan, Y. M. (2013). Effects of kisspeptin on hormone secretion in humans. In A. S. Kauffman \& J. T. Smith (Eds.), Kisspeptin signaling in reproductive biology (Advances in experimental medicine and biology, (Vol. 784, pp. 89-112). New York: Springer.

Cheng, M. (2003). Vocal self-stimulation: From the ring dove story to emotion-based vocal communication. In P. J. B. Slater, J. S. Rosenblatt, C. T. Snowden, T. J. Roper, \& M. Naguib (Eds.), Advances in the Study of Behavior (Vol. 33, pp. 309-354). San Diego: Elsevier.

Clancy, A. N., Singer, A. G., Macrides, F., Bronson, F. H., \& Agosta, W. C. (1988). Experiential and endocrine dependence of gonadotropin responses in male mice to conspecific urine. Biology of Reproduction, 38(1), 183-191.

Coquelin, A., \& Bronson, F. H. (1979). Release of luteinizing hormone in male mice during exposure to females: Habituation of the response. Science, 206(4422), 1099-1101.

Coquelin, A., \& Bronson, F. H. (1980). Secretion of luteinizing hormone in male mice: Factors that influence release during sexual encounters. Endocrinology, 106(4), 1224-1229.

Coquelin, A., Clancy, A. N., Macrides, F., Noble, E. P., \& Gorski, R. A. (1984). Pheromonally induced release of luteinizing hormone in male mice: Involvement of the vomeronasal system. Journal of Neuroscience, 4(9), 2230-2236.

Correa, S. M., Horan, C. M., Johnson, P. A., \& Adkins-Regan, E. (2011). Copulatory behaviors and body condition predict post-mating female hormone concentrations, fertilization success, and primary sex ratios in Japanese quail. Hormones and Behavior, 59(4), 556-564.

Dabbs, J. M., Jr., \& Mohammed, S. (1992). Male and female salivary testosterone concentrations before and after sexual activity. Physiology \& Behavior, 52(1), 195-197.

de Beun, R., Jansen, E., Slangen, J. L., \& Van de Poll, N. E. (1992). Testosterone as appetitive and discriminative stimulus in rats: Sex- and dose-dependent effects. Physiology \& Behavior, 52(4), 629-634.

Delville, Y., Sulon, J., Hendrick, J. C., \& Balthazart, J. (1984). Effect of the presence of females on the pituitary-testicular activity in male Japanese quail (Coturnix coturnix japonica). General and Comparative Endocrinology, 55(2), 295-305. 
Demas, G. E., \& Nelson, R. J. (1998). Social, but not photoperiodic, influences on reproductive function in male Peromyscus aztecus. Biology of Reproduction, 58(2), 385-389.

Dufty, A. M., Jr., \& Wingfield, J. C. (1986). The influence of social cues on the reproductive endocrinology of male brown-headed cowbirds: Field and laboratory studies. Hormones and Behavior, 20(2), 222-234.

Edelstein, R. S., Chopik, W. J., \& Kean, E. L. (2011). Sociosexuality moderates the association between testosterone and relationship status in men and women. Hormones and Behavior, 60(3), 248-255.

Elie, J. E., Mathevon, N., \& Vignal, C. (2011). Same-sex pair-bonds are equivalent to male-female bonds in a life-long socially monogamous songbird. Behavioral Ecology and Sociobiology, 65(12), 2197-2208.

Erskine, M. S., Lehmann, M. L., Cameron, N. M., \& Polston, E. K. (2004). Co-regulation of female sexual behavior and pregnancy induction: An exploratory synthesis. Behavioural Brain Research, 153(2), 295315.

Escasa, M. J., Casey, J. F., \& Gray, P. B. (2011). Salivary testosterone levels in men at a U.S. sex club. Archives of Sexual Behavior, 40(5), 921-926.

Exton, M. S., Bindert, A., Kruger, T., Scheller, F., Hartmann, U., \& Schedlowski, M. (1999). Cardiovascular and endocrine alterations after masturbation-induced orgasm in women. Psychosomatic Medicine, 61(3), 280-289.

Exton, M. S., Kruger, T. H., Bursch, N., Haake, P., Knapp, W., Schedlowski, M., et al. (2001). Endocrine response to masturbation-induced orgasm in healthy men following a 3-week sexual abstinence. World Journal of Urology, 19(5), 377-382.

Flinn, M. V., Ponzi, D., \& Muehlenbein, M. P. (2012). Hormonal mechanisms for regulation of aggression in human coalitions. Human Nature, 23(1), 68-88.

Fox, C. A., Ismail, A. A., Love, D. N., Kirkham, K. E., \& Loraine, J. A. (1972). Studies on the relationship between plasma testosterone levels and human sexual activity. Journal of Endocrinology, 52(1), 51-58.

Gettler, L. T., McDade, T. W., Agustin, S. S., Feranil, A. B., \& Kuzawa, C. W. (2013). Do testosterone declines during the transition to marriage and fatherhood relate to men's sexual behavior? Evidence from the Philippines. Hormones and Behavior, 64(5), 755-763.

Gleason, E. D., \& Marler, C. A. (2010). Testosterone response to courtship predicts future paternal behavior in the California mouse, Peromyscus californicus. Hormones and Behavior, 57(2), 147-154.

Gleason, E. D., Fuxjager, M. J., Oyegbile, T. O., \& Marler, C. A. (2009). Testosterone release and social context: When it occurs and why. Frontiers in Neuroendocrinology, 30(4), 460-469.

Gleason, E. D., Holschbach, M. A., \& Marler, C. A. (2012). Compatibility drives female preference and reproductive success in the monogamous California mouse (Peromyscus californicus) more strongly than male testosterone measures. Hormones and Behavior, 61(1), 100-107.

Goldey, K. L., \& van Anders, S. M. (2011). Sexy thoughts: Effects of sexual cognitions on testosterone, cortisol, and arousal in women. Hormones and Behavior, 59(5), 754-764.

Goldey, K. L., \& van Anders, S. M. (2012). Sexual thoughts: Links to testosterone and cortisol in men. Archives of Sexual Behavior, 41(6), 1461-1470.

Goldey, K. L., Avery, L. R., \& van Anders, S. M. (2014). Sexual fantasies and gender/sex: A multimethod approach with quantitative content and analysis and hormonal responses. Journal of Sex Research, 51(8), 917-931.

Gonçalves, D. M., \& Oliveira, R. F. (2010). Hormones and sexual behavior of teleost fishes. In D. O. Norris \& K. H. Lopez (Eds.), Hormones and Reproduction of Vertebrates (Vol. 1, pp. 119-147). San Diego: Elsevier.

Goodson, J. L. (2013). Deconstructing sociality, social evolution and relevant nonapeptide functions. Psychoneuroendocrinology, 38(4), 465-478.

Goymann, W., Landys, M. M., \& Wingfield, J. C. (2007). Distinguishing seasonal androgen responses from male-male androgen responsiveness: Revisiting the challenge hypothesis. Hormones and Behavior, 51(4), $463-476$.

Graham, J. M., \& Desjardins, C. (1980). Classical conditioning: Induction of luteinizing hormone and testosterone secretion in anticipation of sexual activity. Science, 210(4473), 1039-1041.

Griffith, S. C., Owens, I. P., \& Thuman, K. A. (2002). Extra pair paternity in birds: A review of interspecific variation and adaptive function. Molecular Ecology, 11(11), 2195-2212.

Gutierrez, G., \& Domjan, M. (1997). Differences in the sexual conditioned behavior of male and female Japanese quail (Coturnix japonica). Journal of Comparative Psychology, 111(2), 135-142.

Gwinner, H., Van't Hof, T., \& Zeman, M. (2002). Hormonal and behavioral responses of starlings during a confrontation with males or females at nest boxes during the reproductive season. Hormones and Behavior, 42(1), 21-31.

Hamilton, L. D., \& Meston, C. M. (2010). The effects of partner togetherness on salivary testosterone in women in long distance relationships. Hormones and Behavior, 57(2), 198-202. 
Hamilton, L. D., Fogle, E. A., \& Meston, C. M. (2008). The roles of testosterone and alpha-amylase in exercise-induced sexual arousal in women. The Journal of Sexual Medicine, 5(4), 845-853.

Heiman, J. R., Rowland, D. L., Hatch, J. P., \& Gladue, B. A. (1991). Psychophysiological and endocrine responses to sexual arousal in women. Archives of Sexual Behavior, 20(2), 171-186.

Hellhammer, D. H., Hubert, W., \& Schurmeyer, T. (1985). Changes in saliva testosterone after psychological stimulation in men. Psychoneuroendocrinology, 10(1), 77-81.

Hirschenhauser, K., \& Oliveira, R. F. (2006). Social modulation of androgens in male vertebrates: Metaanalyses of the challenge hypothesis. Animal Behaviour, 71(2), 265-277.

Hirschenhauser, K., Frigerio, D., Grammer, K., \& Magnusson, M. S. (2002). Monthly patterns of testosterone and behavior in prospective fathers. Hormones and Behavior, 42(2), 172-181.

Hirschenhauser, K., Taborsky, M., Oliveira, T., Canàrio, A. V. M., \& Oliveira, R. F. (2004). A test of the 'challenge hypothesis' in cichlid fish: Simulated partner and territory intruder experiments. Animal Behaviour, 68(4), 741-750.

James, P. J., Nyby, J. G., \& Saviolakis, G. A. (2006). Sexually stimulated testosterone release in male mice (Mus musculus): Roles of genotype and sexual arousal. Hormones and Behavior, 50(3), 424-431.

Jerez, S., Rodriguez, C., Cejas, J. R., Bolanos, A., \& Lorenzo, A. (2006). Lipid dynamics and plasma level changes of 17 beta-estradiol and testosterone during the spawning season of gilthead seabream (Sparus aurata) females of different ages. Comparative Biochemistry and Physiology, 143(2), 180-189.

Johansen, J. A., Clemens, L. G., \& Nunez, A. A. (2008). Characterization of copulatory behavior in female mice: Evidence for paced mating. Physiology \& Behavior, 95(3), 425-429.

Jorge, J. C., Velazquez, K. T., Ramos-Ortolaza, D. L., Lorenzini, I., Marrero, J., \& Maldonado-Vlaar, C. S. (2005). A testosterone metabolite is rewarding to ovariectomized female rats. Behavioral Neuroscience, $119(5), 1222-1226$.

Kamel, F., Mock, E. J., Wright, W. W., \& Frankel, A. I. (1975). Alterations in plasma concentrations of testosterone, LH, and prolactin associated with mating in the male rat. Hormones and Behavior, 6(3), 277-288.

Kamel, F., Wright, W. W., Mock, E. J., \& Frankel, A. I. (1977). The influence of mating and related stimuli on plasma levels of luteinizing hormone, follicle stimulating hormone, prolactin, and testosterone in the male rat. Endocrinology, 101(2), 421-429.

Kellam, J. S., Wingfield, J. C., \& Lucas, J. R. (2004). Nonbreeding season pairing behavior and the annual cycle of testosterone in male and female downy woodpeckers, Picoides pubescens. Hormones and Behavior, 46(5), 703-714.

Ketterson, E. D., \& Nolan, V., Jr. (1992). Hormones and life histories: An integrative approach. The American Naturalist, 140, S33-S62.

Ketterson, E. D., Nolan, V., Jr., \& Sandell, M. (2005). Testosterone in females: Mediator of adaptive traits, constraint on sexual dimorphism, or both? American Naturalist, 166(Suppl. 4), 85-98.

Kidd, M. R., O’Connell, L. A., Kidd, C. E., Chen, C. W., Fontenot, M. R., Williams, S. J., et al. (2013). Female preference for males depends on reproductive physiology in the African cichlid fish Astatotilapia burtoni. General and Comparative Endocrinology, 180, 56-63.

Kobayashi, M., Aida, K., \& Hanyu, I. (1986). Gonadotropin surge during spawning in male goldfish. General and Comparative Endocrinology, 62(1), 70-79.

Kraemer, H. C., Becker, H. B., Brodie, H. K., Doering, C. H., Moos, R. H., \& Hamburg, D. A. (1976). Orgasmic frequency and plasma testosterone levels in normal human males. Archives of Sexual Behavior, 5(2), 125-132.

Kruger, T., Exton, M. S., Pawlak, C., von zur Muhlen, A., Hartmann, U., \& Schedlowski, M. (1998). Neuroendocrine and cardiovascular response to sexual arousal and orgasm in men. Psychoneuroendocrinology, 23(4), 401-411.

Kruger, T. H., Haake, P., Chereath, D., Knapp, W., Janssen, O. E., Exton, M. S., et al. (2003). Specificity of the neuroendocrine response to orgasm during sexual arousal in men. Journal of Endocrinology, 177(1), 5764.

Kuzawa, C. W., Gettler, L. T., Huang, Y., \& McDade, T. W. (2010). Mothers have lower testosterone than nonmothers: Evidence from the Philippines. Hormones and Behavior, 57, 441-447.

Lee, P. A., Jaffe, R. B., \& Midgley, A. R., Jr. (1974). Lack of alteration of serum gonadotropins in men and women following sexual intercourse. American Journal of Obstetrics and Gynecology, 120(7), 985-987.

Liley, N. R., Fostier, A., Breton, B., \& Tan, E. S. (1986). Endocrine changes associated with spawning behavior and social stimuli in a wild population of rainbow trout (Salmo gairdneri): II. Females. General and Comparative Endocrinology, 62(1), 157-167.

Lopez, H. H., Hay, A. C., \& Conklin, P. H. (2009). Attractive men induce testosterone and cortisol release in women. Hormones and Behavior, 56(1), 84-92. 
Lord, L. D., Bond, J., \& Thompson, R. R. (2009). Rapid steroid influences on visually guided sexual behavior in male goldfish. Hormones and Behavior, 56(5), 519-526.

Lynch, J. W., Ziegler, T. E., \& Strier, K. B. (2002). Individual and seasonal variation in fecal testosterone and cortisol levels of wild male tufted capuchin monkeys, Cebus apella nigritus. Hormones and Behavior, 41(3), 275-287.

Marshall, R. C., Leisler, B., Catchpole, C. K., \& Schwabl, H. (2005). Male song quality affects circulating but not yolk steroid concentrations in female canaries (Serinus canaria). The Journal of Experimental Biology, 208(24), 4593-4598.

Martinez, I., \& Paredes, R. G. (2001). Only self-paced mating is rewarding in rats of both sexes. Hormones and Behavior, 40(4), 510-517.

McClintock, M. K., \& Adler, N. T. (1978). The role of the female during copulation in wild and domestic Norway rats (Rattus norvegicus). Behaviour, 67(1/2), 67-96.

McClintock, M. K., Anisko, J. J., \& Adler, N. T. (1982). Group mating among Norway rats: II. The social dynamics of copulation: Competition, cooperation, and mate choice. Animal Behaviour, 30(2), 410-425.

McIntyre, M., Gangestad, S. W., Gray, P. B., Chapman, J. F., Burnham, T. C., O’Rourke, M. T., et al. (2006). Romantic involvement often reduces men's testosterone levels-but not always: The moderating role of extrapair sexual interest. Journal of Personality and Social Psychology, 91(4), 642-651.

Meddle, S. L., King, V. M., Follett, B. K., Wingfield, J. C., Ramenofsky, M., Foidart, A., et al. (1997). Copulation activates fos-like immunoreactivity in the male quail forebrain. Behavioural Brain Research, 85(2), 143-159.

Miller, S. L., \& Maner, J. K. (2010). Scent of a woman: Men's testosterone responses to olfactory ovulation cues. Psychological Science, 21(2), 276-283.

Miller, S. L., Maner, J. K., \& McNulty, J. K. (2012). Adaptive attunement to the sex of individuals at a competition: The ratio of opposite-to same-sex individuals correlates with changes in competitors' testosterone levels. Evolution and Human Behavior, 33(1), 57-63.

Moore, M. C. (1982). Hormonal response of free-living male white-crowned sparrows to experimental manipulation of female sexual behavior. Hormones and Behavior, 16(3), 323-329.

Moore, M. C. (1983). Effect of female sexual displays on the endocrine physiology and behaviour of male white-crowned sparrows, Zonotrichia leucophrys. Journal of Zoology, 199(2), 137-148.

Muehlenbein, M. P. (2006). Adaptive variation in testosterone levels in response to immune activation: Empirical and theoretical perspectives. Social Biology, 53(1-2), 13-23.

Muehlenbein, M. P., \& Bribiescas, R. G. (2005). Testosterone-mediated immune functions and male life histories. American Journal of Human Biology, 17(5), 527-558.

Muller, M. N., \& Wrangham, R. W. (2004). Dominance, aggression and testosterone in wild chimpanzees: A test of the 'challenge hypothesis'. Animal Behaviour, 67(1), 113-123.

Munakata, A., \& Kobayashi, M. (2010). Endocrine control of sexual behavior in teleost fish. General and Comparative Endocrinology, 165(3), 456-468.

Murcia, C. Q., Bongard, S., \& Kreutz, G. (2009). Emotional and neurohumoral responses to dancing Tango Argentino: The effects of music and partner. Music and Medicine, 1(1), 14-21.

Navarro, V. M. (2012). New insights into the control of pulsatile GnRH release: The role of Kiss1/neurokinin B neurons. Frontiers in Endocrinology, 3, article 48.

Nyby, J. G. (2008). Reflexive testosterone release: A model system for studying the nongenomic effects of testosterone upon male behavior. Frontiers in Neuroendocrinology, 29(2), 199-210.

O’Connell, M. E., Reboulleau, C., Feder, H. H., \& Silver, R. (1981a). Social interactions and androgen levels in birds: I. Female characteristics associated with increased plasma androgen levels in the male ring dove (Streptopelia risoria). General and Comparative Endocrinology, 44(4), 454-463.

O’Connell, M. E., Silver, R., Feder, H. H., \& Reboulleau, C. (1981b). Social interactions and androgen levels in birds: II. Social factors associated with a decline in plasma androgen levels in male ring doves (Streptopelia risoria). General and Comparative Endocrinology, 44(4), 464-469.

O’Connell, L. A., Rigney, M. M., Dykstra, D. W., \& Hofmann, H. A. (2013). Neuroendocrine mechanisms underlying sensory integration of social signals. Journal of Neuroendocrinology, 25(7), 644-654.

Oliveira, R. F. (2009). Social behavior in context: Hormonal modulation of behavioral plasticity and social competence. Integrative and Comparative Biology, 49(4), 423-440.

Oliveira, R. F., Almada, V. C., \& Canario, A. V. (1996). Social modulation of sex steroid concentrations in the urine of male cichlid fish Oreochromis mossambicus. Hormones and Behavior, 30(1), 2-12.

Persaud, K. N., \& Galef, B. G., Jr. (2004). Fertilized female quail avoid conspecific males: Female tactics when potential benefits of new sexual encounters are reduced. Animal Behaviour, 68(6), 1411-1416.

Persaud, K. N., \& Galef, B. G., Jr. (2005). Female Japanese quail (Coturnix japonica) mated with males that harassed them are unlikely to lay fertilized eggs. Journal of Comparative Psychology, 119(4), 440-446. 
Peters, A., Astheimer, L. B., \& Cockburn, A. (2001). The annual testosterone profile in cooperatively breeding superb fairy-wrens, Malurus cyaneus, reflects their extreme infidelity. Behavioral Ecology and Sociobiology, 50(6), 519-527.

Peters, A., Schweiger, U., Pellerin, L., Hubold, C., Oltmanns, K. M., Conrad, M., et al. (2004). The selfish brain: Competition for energy resources. Neuroscience and Biobehavioral Reviews, 28(2), 143-180.

Pfaus, J. G., Kippin, T. E., Coria-Avila, G. A., Gelez, H., Afonso, V. M., Ismail, N., et al. (2012). Who, what, where, when (and maybe even why)? How the experience of sexual reward connects sexual desire, preference, and performance. Archives of Internal Medicine, 41(1), 31-62.

Phoenix, C. H., Dixson, A. F., \& Resko, J. A. (1977). Effects of ejaculation on levels of testosterone, cortisol, and luteinizing hormone in peripheral plasma of rhesus monkeys. Journal of Comparative and Physiological Psychology, 91(1), 120-127.

Pinxten, R., de Ridder, E., \& Eens, M. (2003). Female presence affects male behavior and testosterone levels in the european starling (Sturnus vulgaris). Hormones and Behavior, 44(2), 103-109.

Pirke, K. M., Kockott, G., \& Dittmar, F. (1974). Psychosexual stimulation and plasma testosterone in man. Archives of Sexual Behavior, 3(6), 577-584.

Prasad, A., Mumford, S. L., Buck Louis, G. M., Ahrens, K. A., Sjaarda, L. A., Schliep, K. C., et al. (2014). Sexual activity, endogenous reproductive hormones and ovulation in premenopausal women. Hormones and Behavior, 66(2), 330-338.

Preti, G., Wysocki, C. J., Barnhart, K. T., Sondheimer, S. J., \& Leyden, J. J. (2003). Male axillary extracts contain pheromones that affect pulsatile secretion of luteinizing hormone and mood in women recipients. Biology of Reproduction, 68(6), 2107-2113.

Purvis, K., Landgren, B. M., Cekan, Z., \& Diczfalusy, E. (1976). Endocrine effects of masturbation in men. Journal of Endocrinology, 70(3), 439-444.

Pyter, L. M., Neigh, G. N., \& Nelson, R. J. (2005). Social environment modulates photoperiodic immune and reproductive responses in adult male white-footed mice (Peromyscus leucopus). American Journal of Physiology, 288(4), R891-R896.

Rangel-Negrin, A., Dias, P. A., Chavira, R., \& Canales-Espinosa, D. (2011). Social modulation of testosterone levels in male black howlers (Alouatta pigra). Hormones and Behavior, 59(1), 159-166.

Redoute, J., Stoleru, S., Gregoire, M. C., Costes, N., Cinotti, L., Lavenne, F., et al. (2000). Brain processing of visual sexual stimuli in human males. Human Brain Mapping, 11(3), 162-177.

Ronay, R., \& von Hippel, W. (2010). The presence of an attractive woman elevates testosterone and physical risk taking in young men. Social Psychological and Personality Science, 1(1), 57-64.

Roney, J. R., \& Simmons, Z. L. (2012). Men smelling women: Null effects of exposure to ovulatory sweat on men's testosterone. Evolutionary Psychology, 10(4), 703-713.

Roney, J., Mahler, S. V., \& Maestripieri, D. (2003). Behavioral and hormonal responses of men to brief interactions with women. Evolution and Human Behavior, 24(6), 365-375.

Roney, J. R., Lukaszewski, A. W., \& Simmons, Z. L. (2007). Rapid endocrine responses of young men to social interactions with young women. Hormones and Behavior, 52(3), 326-333.

Roney, J. R., Simmons, Z. L., \& Lukaszewski, A. W. (2010). Androgen receptor gene sequence and basal cortisol concentrations predict men's hormonal responses to potential mates. Proceedings of the Royal Society B, 277(1678), 57-63.

Rowland, D. L., Heiman, J. R., Gladue, B. A., Hatch, J. P., Doering, C. H., \& Weiler, S. J. (1987). Endocrine, psychological and genital response to sexual arousal in men. Psychoneuroendocrinology, 12(2), 149-158.

Rupp, H. A., \& Wallen, K. (2007). Relationship between testosterone and interest in sexual stimuli: The effect of experience. Hormones and Behavior, 52(5), 581-589.

Sagarin, B. J., Cutler, B., Cutler, N., Lawler-Sagarin, K. A., \& Matuszewich, L. (2009). Hormonal changes and couple bonding in consensual sadomasochistic activity. Archives of Sexual Behavior, 38(2), 186-200.

Sandell, M. I., Smith, H. G., \& Bruun, M. (1996). Paternal care in the European starling, Sturnus vulgaris: Nestling provisioning. Behavioral Ecology and Sociobiology, 39(5), 301-309.

Sessa, A. K., Harris, R. M., \& Hofmann, H. A. (2013). Sex steroid hormones modulate responses to social challenge and opportunity in males of the monogamous convict cichlid, Amatitliana nigrofasciata. General and Comparative Endocrinology, 189, 59-65.

Simmons, Z. L., \& Roney, J. R. (2009). Androgens and energy allocation: Quasi-experimental evidence for effects of influenza vaccination on men's testosterone. American Journal of Human Biology, 21(1), 133135.

Snowdon, C. T., Ziegler, T. E., Schultz-Darken, N. J., \& Ferris, C. F. (2006). Social odours, sexual arousal and pairbonding in primates. Philosophical Transactions of the Royal Society B, 361(1476), 2079-2089.

Stárka, L., Hill, M., Havlíková, H., Kancheva, L., \& Sobotka, V. (2006). Circulating neuroactive C 21-and C 19-steroids in young men before and after ejaculation. Physiological Research, 55(4), 429-436. 
Stearns, E. L., Winter, J. S., \& Faiman, C. (1973). Effects of coitus on gonadotropin, prolactin and sex steroid levels in man. Journal of Clinical Endocrinology and Metabolism, 37(5), 687-691.

Stokkan, K. A., \& Sharp, P. J. (1980). Seasonal changes in the concentrations of plasma luteinizing hormone and testosterone in willow ptarmigan (Lagopus lagopus lagopus) with observations on the effects of permanent short days. General and Comparative Endocrinology, 40(1), 109-115.

Stoleru, S., Ennaji, A., Cournot, A., \& Spira, A. (1993). LH pulsatile secretion and testosterone blood levels are influenced by sexual arousal in human males. Psychoneuroendocrinology, 18(3), 205-218.

Stoleru, S., Gregoire, M. C., Gerard, D., Decety, J., Lafarge, E., Cinotti, L., et al. (1999). Neuroanatomical correlates of visually evoked sexual arousal in human males. Archives of Sexual Behavior, 28(1), 1-21.

Strier, K. B., Ziegler, T. E., \& Wittwer, D. J. (1999). Seasonal and social correlates of fecal testosterone and cortisol levels in wild male muriquis (Brachyteles arachnoides). Hormones and Behavior, 35(2), 125-134.

Strier, K. B., Lynch, J. W., \& Ziegler, T. E. (2003). Hormonal changes during the mating and conception seasons of wild northern muriquis (Brachyteles arachnoides hypoxanthus). American Journal of Primatology, 61(2), 85-99.

Strom, J. O., Ingberg, E., Druvefors, E., Theodorsson, A., \& Theodorsson, E. (2012). The female menstrual cycle does not influence testosterone concentrations in male partners. Journal of Negative Results in Biomedicine, 11, article 1.

van Anders, S. M. (2013). Beyond masculinity: Testosterone, gender/sex, and human social behavior in a comparative context. Frontiers in Neuroendocrinology, 34(3), 198-210.

van Anders, S. M., \& Goldey, K. L. (2010). Testosterone and partnering are linked via relationship status for women and 'relationship orientation' for men. Hormones and Behavior, 58(5), 820-826.

van Anders, S. M., \& Watson, N. V. (2006). Social neuroendocrinology: Effects of social contexts and behaviors on sex steroids in humans. Human Nature, 17(2), 212-237.

van Anders, S. M., Hamilton, L. D., Schmidt, N., \& Watson, N. V. (2007). Associations between testosterone secretion and sexual activity in women. Hormones and Behavior, 51(4), 477-482.

van Anders, S. M., Brotto, L., Farrell, J., \& Yule, M. (2009). Associations among physiological and subjective sexual response, sexual desire, and salivary steroid hormones in healthy premenopausal women. Journal of Sexual Medicine, 6(3), 739-751.

van Anders, S. M., Goldey, K. L., \& Kuo, P. X. (2011). The steroid/peptide theory of social bonds: Integrating testosterone and peptide responses for classifying social behavioral contexts. Psychoneuroendocrinology, 36(9), 1265-1275.

van der Meij, L., Buunk, A. P., van de Sande, J. P., \& Salvador, A. (2008). The presence of a woman increases testosterone in aggressive dominant men. Hormones and Behavior, 54(5), 640-644.

van der Meij, L., Almela, M., Buunk, A. P., Fawcett, T. W., \& Salvador, A. (2012). Men with elevated testosterone levels show more affiliative behaviours during interactions with women. Proceedings of the Royal Society B, 279(1726), 202-208.

Vasey, P. L. (2006). The pursuit of pleasure: An evolutionary history of female homosexual behavior in Japanese macaques. In V. Sommer \& P. L. Vasey (Eds.), Homosexual behavior in animals: An evolutionary perspective (pp. 191-219). New York: Cambridge University Press.

Vasey, P. L., \& Sommer, V. (2006). Homosexual behavior in animals: Topics, hypotheses, and research trajectories. In V. Sommer \& P. L. Vasey (Eds.), Homosexual behavior in animals: An evolutionary perspective (pp. 3-42). New York: Cambridge University Press.

Wallen, K. (2001). Sex and context: Hormones and primate sexual motivation. Hormones and Behavior, 40(2), 339-357.

Wallen, K., \& Zehr, J. L. (2004). Hormones and history: The evolution and development of primate female sexuality. Journal of Sex Research, 41(1), 101-112.

Welling, L. L. M., Jones, B. C., DeBruine, L. M., Conway, C. A., Law Smith, M. J., Little, A. C., et al. (2007). Raised salivary testosterone in women is associated with increased attraction to masculine faces. Hormones and Behavior, 52(2), 156-161.

Welling, L. L. M., Jones, B. C., DeBruine, L. M., Smith, F. G., Feinberg, D. R., Little, A. C., et al. (2008). Men report stronger attraction to femininity in women's faces when their testosterone levels are high. Hormones and Behavior, 54(5), 703-708.

Welling, L. L., Persola, L., Wheatley, J. R., Cárdenas, R. A., \& Puts, D. A. (2013). Competition and men's face preferences. Personality and Individual Differences, 54(3), 414-419.

Wingfield, J. C., Hegner, R. E., Dufty, A. M., Jr., \& Ball, G. F. (1990). The "challenge hypothesis": Theoretical implications for patterns of testosterone secretion, mating systems, and breeding strategies. American Naturalist, 136(6), 829-846.

Wingfield, J. C., Lynn, S., \& Soma, K. K. (2001). Avoiding the 'costs' of testosterone: Ecological bases of hormone-behavior interactions. Brain, Behavior and Evolution, 57(5), 239-251. 
Wood, R. I. (2004). Reinforcing aspects of androgens. Physiology \& Behavior, 83(2), 279-289.

Yamaguchi, T., Watanuki, H., \& Sakai, M. (2001). Effects of estradiol, progesterone and testosterone on the function of carp, Cyprinus carpio, phagocytes in vitro. Comparative Biochemistry and Physiology, $129(1), 49-55$

Ziegler, T. E., Schultz-Darken, N. J., Scott, J. J., Snowdon, C. T., \& Ferris, C. F. (2005). Neuroendocrine response to female ovulatory odors depends upon social condition in male common marmosets, Callithrix jacchus. Hormones and Behavior, 47(1), 56-64.

Zilioli, S., Caldbick, E., \& Watson, N. V. (2014). Testosterone reactivity to facial display of emotions in men and women. Hormones and Behavior, 65(5), 461-468. 